\title{
The wings before the bird: an evaluation of flapping-based locomotory hypotheses in bird antecedents
}

\author{
T. Alexander Dececchi, Hans CE Larsson, Michael B Habib
}

Background. Powered flight is implicated as a major driver for the success of birds. Here we examine the effectiveness of three hypothesized pathways for the evolution of the flight stroke, the forelimb motion that powers aerial locomotion, in a terrestrial setting across a range of stem and basal avians: flap running, Wing Assisted Incline Running (WAIR), and wing-assisted leaping.

Methods. Using biomechanical mathematical models based on known aerodynamic principals and in vivo experiments and ground truthed using extant avians we seek to test if an incipient flight stroke may have contributed sufficient force to permit flap running, WAIR, or leaping takeoff along the phylogenetic lineage from Coelurosauria to birds

Results. None of these behaviours were found to meet the biomechancial threshold requirements before Paraves. Neither was there a continuous trend of refinement for any of these biomechanical performances across phylogeny nor a signal of universal applicability near the origin of birds. None of these flap-based locomotory models appear to have been a major influence on pre-flight character acquisition such as pennaceous feathers, suggesting non-locomotory behaviours, and less stringent locomotory behaviours such as balancing and braking, played a role in the evolution of the maniraptoran wing and nascent flight stroke. We find no support for widespread prevalence of WAIR in non-avian theropods, but can't reject its presence in large winged, small-bodied taxa like Microraptor and Archaeopteryx.

Discussion. Using our first principles approach we find that "near flight" locomotor behaviors are most sensitive to wing area, and that non-locomotory related selection regimes likely expanded wing area well before WAIR and other such behaviors were possible in derived avians. These results suggest that investigations of the drivers for wing expansion and feather elongation in theropods need not be intrinsically linked to locomotory adaptations, and this separation is critical for our understanding of the origin of powered flight and avian evolution. 
3 The wings before the bird: an evaluation of flapping-based locomotory hypotheses in bird antecedents

5 Dececchi ${ }^{1 *}$, T. Alexander; Larsson², HCE and MB Habib ${ }^{3}$

6

7 - corresponding author

8 1. Department of Geological Sciences and Geological Engineering, Queen's

$9 \quad$ University, Kingston, Ontario, Canada, K7L 3N6. Email. td50@queensu.ca

10 2. Redpath Museum, McGill University, 859 Sherbrooke Street West Montreal,

11 Quebec, Canada, H3A 0C4

12 3. Keck School of Medicine of University of Southern California, Department of Cell 13 and Neurobiology, Los Angeles, CA, USA, 90089-9112 


\section{ABSTRACT}

25

Background. Powered flight is implicated as a major driver for the success of birds.

Here we examine the effectiveness of three hypothesized pathways for the evolution of the flight stroke, the forelimb motion that powers aerial locomotion, in a terrestrial setting across a range of stem and basal avians: flap running, Wing Assisted Incline Running (WAIR), and wing-assisted leaping. Methods. Using biomechanical mathematical models based on known aerodynamic principals and in vivo experiments and ground truthed using extant avians we seek to test if an incipient flight stroke may have contributed sufficient force to permit flap running, WAIR, or leaping takeoff along the phylogenetic lineage from Coelurosauria to birds Results. None of these behaviours were found to meet the biomechancial threshold requirements before Paraves. Neither was there a continuous trend of refinement for any of these biomechanical performances across phylogeny nor a signal of universal applicability near the origin of birds. None of these flap-based locomotory models appear to have been a major influence on pre-flight character acquisition such as pennaceous feathers, suggesting non-locomotory behaviours, and less stringent locomotory behaviours such as balancing and braking, played a role in the evolution of the maniraptoran wing and nascent flight stroke. We find no support for widespread prevalence of WAIR in nonavian theropods, but can't reject its presence in large winged, small-bodied taxa like Microraptor and Archaeopteryx. Discussion. Using our first principles approach we find that "near flight" locomotor behaviors are most sensitive to wing area, and that nonlocomotory related selection regimes likely expanded wing area well before WAIR and other such behaviors were possible in derived avians. These results suggest that 
47 investigations of the drivers for wing expansion and feather elongation in theropods

48 need not be intrinsically linked to locomotory adaptations, and this separation is critical

49 for our understanding of the origin of powered flight and avian evolution.

50

51

52

53

54

55

56

57

58

59

60

61

62

63

64

65

66

67

68

69

\section{INTRODUCTION}

Evolution of powered flight in vertebrates was a key innovation that spurred the evolutionary success of birds, bats, and pterosaurs (Sears et al. 2006; Butler et al. 2009; Benson and Choiniere 2013). Of the three radiations, the theropod to bird transition has garnered the most interest and scholarship due to the higher quality of the fossil record documenting the origin and refinement of their flight including: the evolution of feathers, reduced body size, an avian-like physiology and respiration, elongate forelimbs, and modifications of the pectoral and forelimb musculoskeletal system (Baier et al. 2007; Codd et al. 2008; Dececchi and Larsson 2009, 2013; Makovicky and Zanno 2011; Benson and Choiniere 2013; Brusatte et al. 2014; Xu et al. 2014). Despite the wealth of fossil evidence documenting this transition deducing the origin and subsequent evolution of the flight stroke, a biomechanical innovation that permitted aerial locomotion, remains elusive.

The flight stroke of extant birds traces a complex ellipsoidal path that is controlled by derived muscle origins and insertions and modified shoulder, elbow, and wrist joints and ligaments (Gatesy and Baier 2005). Many antecedent functions of the flight stroke have been proposed. These include a raptorial function of the forelimbs for fast prey capture (Ostrom 1974), behavioural precursors such as courtship, balance, or warning 
70 displays (Fowler et al. 2011; Foth et al. 2014), as well as locomotory functions (Caple et 71 al. 1983; Dial 2003; Chatterjee and Templin 2007).

Powered flight differs from gliding flight in that it uses active flapping to generate

73 thrust. Some models of the origin of avian flight propose antecedents living in trees and 74 deriving the flight stroke from a parachuting or gliding stage (Chatterjee and Templin 2004; Alexander et al. 2010; Dyke et al. 2013) based primarily on the observation that many modern arboreal tetrapods perform similar behaviors (Dudley et al. 2007;

77 Evangelista et al. 2014). Yet nearly all stem avians have hindlimb morphologies that 78 compare most closely to extant cursorial tetrapods (Dececchi and Larsson 2011) and a multivariate analysis of limb element lengths recovered the earliest birds as most similar to extant terrestrial foragers (Bell and Chiappe 2011; Mitchell and Makovicky 2014). The only theropod taxa that may diverge from this are Scansoriopterygidae, a clade known from four small, fragmentary specimens, but presenting intriguing and radically divergent morphologies from other maniraptoran theropods. Notably, when preserved, they possess large pedal and manual phalangeal indices, a reduced crural index, a reduced hindlimb length, and reduced limb integument not seen in avian antecedents, including paravians (Glen and Bennett 2007; Bell and Chiappe 2011; Dececchi and Larsson 2011; Dececchi et al. 2012). One scansoriopterygid may even possess a skin patagium that may have functioned as an airfoil (Xu et al. 2015). These putative gliding structures are extremely divergent from other theropods and likely represent a convergent pathway to becoming volant. 
93 (Burgers and Chiappe 1999), wing assisted incline running or WAIR (Dial 2003), and

94 vertical leaping (Caple et al. 1983). Behaviors in the second category are non-

95 locomotory behaviors, such as balancing during prey capture (Fowler et al. 2011) and

96 braking during high-speed turns (Schaller 2008). The three stringent locomotory

97 behaviours (WAIR, flap running and vertical leaping) are variations on a proto-flight

98 stroke assisting in force generation to increase ground and launch velocities (Burgers

99 and Chiappe 1999) or to assist in ascending steep inclines to facilitate escape to

100 elevated refuges such as into trees or up inclined rock faces (Dial 2003). All three are

101 present throughout much of extant bird diversity and have been areas of research into

102 the possible pathways for the origins of powered flight.

103 WAIR is a behaviour observed primarily as a means of predator escape,

104 especially in pre-flight capable juveniles (Tobalske and Dial 2007; Dial et al. 2008;

105 Jackson et al. 2009; Heers and Dial 2012; Heers et al. 2014). This has been suggested

106 to provide a series of functional and morphological stages using immature age classes

107 of extant individuals as proxies for transitional evolutionary stages from basal

108 coelurosaurs to volant birds (Dial et al. 2006; Heers and Dial 2012). This has been most

109 thoroughly studied in the Chukar partridge (Alectornis chukar, hereafter referred to as

110 Chukars), though work has been done in other extant birds such as the Brush Turkey

111 (Alectura lathami) and Peafowl (Pavo cristatus) (Heers and Dial 2015). At the earliest

112 juvenile stages Chukars ( $0-5$ days post hatching [dph] and $<20 \mathrm{~g}$ ) either crawl or

113 asymmetrically flap their wings to produce forces of approximately $6-10 \%$ of their body

114 weight (Jackson et al. 2009; Heers et al. 2011; 2014) to ascend inclines of less than

$11565^{\circ}$, slightly greater than the level that they can ascend using their legs alone $\left(55-60^{\circ}\right)$ 
116 (Dial and Bundle 2003; Dial et al.2006). At these low angles, the primary locomotory

117 forces are generated from the hindlimbs but this changes when higher angles are

118 attempted (Bundle and Dial 2003). To ascend to sub vertical angles, juvenile and older

119 individuals must produce forces equaling a minimum of $50 \%$ of their body weight (Dial

120 and Jackson 2010). Larger birds with masses greater than $0.8 \mathrm{~kg}$ such as adult Brush

121 Turkeys or Peafowl struggle to WAIR at this level (Dial and Jackson 2010; Heers et al.

122 2015). Low angle WAIR has been hypothesized to be present throughout Coelurosauria

123 and sub vertical WAIR minimally at Paraves (Dial 2003, Heers et al. 2012, 2014).

$124 \quad$ Vertical leaping (both from the ground and perches) begins as an effectively

125 ballistic process in flying animals, initiated by the hindlimbs in birds (Heppner and

126 Anderson 1985; Bonser and Rayner 1996; Earls 2000; Tobalske et al. 2004), bats

127 (Schutt et al. 1997; Gardiner and Nudds 2011), and insects (Nachtigall and Wilson

128 1967; Nachtigall 1968, 1978; Schouest et al. 1986; Trimarchi and Schneiderman 1995;

129 Dudley 2002). Immediately after the ballistic phase is initiated, the wings are engaged

130 for the climb out phase of launch. Leaping takeoffs are common among small to

131 medium sized birds (Provini et al. 2012) but are also present in many larger birds

132 including Turkeys (Tobalske and Dial 2000), Peafowl (Askew 2014), Tinamou (Silveria

133 et al. 2001) as well as herons, storks, eagles, and vultures (pers. obs.). The largest

134 living flying birds, Kori bustards, are documented to use a very short run before launch

135 (Prozesky, 1970), though large captive specimens have demonstrated a true leaping

136 takeoff, as well (pers. obs. MBH). Caple et al. (1983) proposed as a model for the origin

137 of flight in birds, especially in smaller taxa. Flap-running is used in some extant birds,

138 especially semi aquatic species, to accelerate to takeoff speeds whether starting from a 
139 water or land launch (though mostly associated with compliant surfaces, e.g. water 140 see Earls, 2000).

141

142 Here we present biomechanical models to test when and if a flight stroke may have 143 contributed to flap running, WAIR, or leaping takeoff along the phylogenetic lineage

144 from Coelurosauria to birds and if these models coincide with the evolution of 145 pennaceous feathers and musculoskeletal adaptations for flight. Our goal is to take 146 evolutionary narratives about pathways to flight origins and evaluate them using 147 quantitative, mechanical models derived from living birds. Although feathery integument 148 is likely to have been a synapomorphy for all dinosaurs and perhaps even all 149 ornithodirans (Godefroit et al. 2014 but see Barrett et al. 2015), the evolution of 150 pennaceous forelimb and hindlimb feathers has been hypothesized to have been driven 151 by selection for locomotion (Burgers and Chiappe 1999; Xu et al. 2003; Dial 2006;

152 Heers et al. 2011). Thus we set up a testing regime to determine if non-avian theropods 153 could produce biomechanical values that fit within the realms of those measured in 154 modern animals exhibiting these behaviors, and if is there a decoupling of the timing of 155 the success in these behaviours from the origin of previous proposed flight related traits.

\section{MATERIALS AND METHODS}

Due to uncertainty regarding soft tissues in fossil organisms, some variables were treated as constants in the taxa modeled and based on values for extant birds. These include feather material properties, arrangement and muscle power. Using these values provided conservative estimates in the sense that they would yield more capable 
162 performances for taxa that may lie near biomechanical thresholds. Wing feather

163 arrangements for some fossils appear to be similar to modern birds (Elzanowski 2002;

164 Xu et al. 2003; Foth et al. 2014) though for some taxa this has been disputed (Xu et al.

165 2010b; Longrich et al. 2012).

166 A greater source of uncertainty and debate is fraction of forelimb muscle mass

167 that is due to the M. pectoralis and its potential power output. Extant birds have

168 extremely large wing muscles, as a proportion to their bodyweight (Marden 1987). The

169 mass of M. pectoralis for birds' ranges between $10-20 \%$ of total body mass (Greenewalt

170 1975; Askew et al. 2001), and total flight muscle fractions for birds can reach $40 \%$

171 (Hartman 1961; Greenewalt 1962). This is significantly larger than that estimated in

172 non-avian theropods or early birds. For example, Archaeopteryx's pectoral muscles are

173 estimated at only $0.5 \%$ of its body mass (Bock 2013) with the entire forelimb (including

174 bone and all other tissues) at 11-14\% (Allen et al. 2013). For our analysis we calculated

175 values for power available from the forelimb and hindlimb based on the assumption that

176 non-avian theropods had forelimb muscle mass fractions of $10 \%$ their total mass and

177 that hindlimb muscle mass fractions were $30 \%$ of total mass. These values are likely

178 significant overestimations for non-paravians pectoral regions, but the pelvic region

179 values are within the range previous estimated for non-avian maniraptorans (Allen et al.

180 2013), whose estimates do not include the M. caudofemoralis. The pectoral muscle

181 values we assigned are similar to estimates of pectoral region mass in Microraptor and

182 Archaeopteryx, though those estimates are based on the entire pectoral region tissues

183 (except feathers) and thus the relative mass of the pectoral musculature is likely

184 smaller. 
Yet power and muscle mass may not be the main determinant for the use of

wings as locomotory structures. Jackson et al. (2011) estimated that pigeons, with

approximately $20 \%$ of their body mass as pectoralis muscles, only used approximately $10 \%$ of their mass-specific power for low angle WAIR. Further, it has been suggested

that power output itself may not determine flight ability, but lift to power ratio (Marden

1987). For this analysis we have assumed extant bird power productions and metabolic capacities for short "burst" activities for non-avian theropods and early birds. Although

paravian metabolism was not at the levels seen in extant birds, it was sufficient to perform short burst activities (Erickson et al. 2009). Regardless, as our methodology uses wing-beat frequency in conjunction with body size and wing arc measures to generate a lift production value, we are not dependent on either theory (power or lift force) to produce meaningful results.

\section{Taxonomic sampling}

Forty-five specimens representing twenty-four non-avian theropod taxa and five

avian taxa were examined. Non-avian theropod specimens ranged in mass from

approximately $60 \mathrm{~g}$ to $18 \mathrm{~kg}$ (Table 1 , Table S1). Of these, twenty-eight are from specimens accounting for twelve non-avian theropod taxa with preserved feather material, the rest are from closely related taxa that are inferred to be feathered and were included to broaden the scope of the maniraptorans represented. We a priori excluded the tyrannosaurids Yutyrannus, because of its large size (estimated mass $\sim 1400 \mathrm{~kg}$ ), and Dilong, due to its incompletely preserved forelimb. Multiple individuals 
208 were included for Anchiornis, Similicaudipteryx, Caudipteryx, Microraptor,

209 Sinosauropteryx, Mei, Archaeopteryx, Jeholornis, and Sapeornis to represent different

210 size classes and ontogenetic stages as different stages in ontogeny may have different

211 life history strategies (Parsons and Parsons 2015). To address the possibility of WAIR

212 in juvenile but not adult members of Pennaraptora, three late stage embryos: MOR 246-

2131 Troodon formosus per Varricchio et al. (2002), MPC-D100/971

214 Citipati osmolskea and MPC-D100/1018 Oviraptor incertae sedis per Yu et al. (2013)

215 were included in this analysis. These specimens are incomplete, but forelimb lengths

216 could be estimated based on the fact that the humerus / forelimb ratio in non-avian and

217 basal avian theropods does not change significantly across ontogeny (Table S2). We

218 used the value of $\sim 43 \%$ MOR $246-1$ based on the ratios seen in other Troodontids

219 (range between 39-45\%) based on Mei, Jinfengopteryx, Anchiornis, Aurornis,

220 Sinovenator, Sinornithoides and Xiaotingia. For MPC-D100/971 and MPC-D100/1018

221 we used $41 \%$ based on Citipati. For all late stage embryos we reconstructed wing area

222 as if they possessed wings with pennaceous feathering proportional to that seen in

223 adults. This is likely an overestimation, as hatchling and young juveniles in other non-

224 avian theropods do not show pennaceous development to the extent of adults (Xu et al.

2252009 , Zelenitszky et al. 2012).

226

Mass estimations for non-avian theropods were based on values for femur length

228 (Christiansen and Fariña 2004) except for Yixianosaurus, which has no preserved

229 hindlimbs, for whom upper and lower mass estimate boundaries were taken from

230 Dececchi et al. (2012). As non-avian and avian theropods show significant difference in 
231 hindlimb scaling (Dececchi and Larsson 2013), this method could not be applied to the

232 avian theropods in our dataset. For birds, two mass estimates were generated from the

233 regressions derived from humerus length equations of extant birds (Liu et al. 2012; Field

234 et al. 2013), this element was selected as it showed high correlation values in both

235 source datasets and were easily computable for all specimens. Nodal values were

236 calculated based on a modified version of the phylogeny in Dececchi and Larsson 2013

237 (Data S1).

238

239

\section{Wing dimensions}

240

Wing length was calculated based on the length of the humerus, ulna,

metacarpal II, and the longest primary feather length, arranged in a straight line.

242

Metacarpal length was used instead of total manus length as the longest primaries

attach to the metacarpals and distal forelimb in paravians (Savile 1957; Elzanowski

2002; Xu et al. 2010a; Foth et al. 2014). This gives values similar to those previously

reported for maximal straight-line length of the wing in Archaeopteryx, differing by less

than $1 \%$ (Yalden 1971). Wing area was estimated using a chord value $65 \%$ of maximum

primary length based on the differences between the longest primary feather and the

shortest, distal primary in Archaeopteryx (Elzanowski 2000; Foth et al. 2014) and

Caudipteryx (Ji et al. 1998). This estimate produces a greater wing area, by $15 \%$, than

what was calculated by Yalden (1971) for the Berlin specimen of Archaeopteryx and

251

produces similar overestimations for other paravian taxa with publisehd wing areas such

over that of Alexander et al. 2010) .and Zhenyuanlong ( $5 \%$ greater than calculated by 
254 Liu and Brussatte 2015). Therefore we treat our values as upper bound estimates of 255 maximum wing area as they are also overestimates of functional wing area since they 256 ignore the natural flexed position that the limbs take during locomotion. We used this 257 value for our primary analysis as it gives highest possible values for all our force 258 production data and thus the maximum likelihood of success in achieving the minimum 259 threshold values indicating the possible presence of a behavior in said taxon. For taxa 260 without primary feathers preserved (Table 1), we estimated their length based on either 261 other members of the same genus or closely related taxa and assuming congruent 262 lengths. We estimated body width using furcular widths (Table S3) this represents an 263 addition of between $10-15 \%$ to the value of the non-avian theropod skeletal arm span. 264 In extant bird wings feathers add another $40+\%$ to skeletal arm length (Nudds et al. 265 2007) and proportionally more in many non-avian theropods (Table 1). Wingspan was set 2.1 times wing length (feather lengths included) to assure we did not underestimate the potential wingspan and the influence of the body on wing area in non-avian taxa.

\section{Model construction}

To test WAIR, flap running, and vertical leaping we used equations based on those of

271 Burgers and Chiappe (1999) and on extant bird flight work in Pennycuick (2008) to 272 estimate force production in a similar context to what is examined here.

$\mathrm{bw}=0.5 \mathrm{Cl}{ }^{*} p^{*}(f \mathrm{Amp}+\mathrm{U})^{2} \mathrm{~S} / 9.8^{*} \mathrm{M}$

275

276 Where bw denotes the proportion of body weight supported by the lift generated by the 277 wings (see Supplemental materials section S4 for more complete description of all 
278 formula and calculations). This relatively simple model was chosen as it is easier to 279 update with new paleobiological information and allowed us to see directly the result of 280 varying the input data to see how varying models of theropod functional limitations 281 shape the results. To test the accuracy of our model, we compared our body weight 282 support results to published data for Chukar partridges during WAIR across the three ontogenetic stages, Pigeon data during WAIR, and birds during takeoff (Table 2). Our values are within the range seen in published data for all three stages of WAIR development and show values greater than 1.0 for all birds undertaking leaping takeoff. As our simple model accurately matches real world experimentally derived values of extant taxa, we believe it a suitable starting point to derive comparative force production data for fossil avian and non-avian theropods.

\section{Creation of Benchmarks}

291

292
As WAIR ability is not uniform across ontogeny and seems to be linked to force production (Dial et al. 2012), we created two-benchmarks of proportion of body mass supported for taxa to reach. Values between $0.06-0.49$ body weight (bw) are classified as level 1 WAIR, which corresponds to the earliest stages of ontogeny and sub vertical ascents (late stage I and early stage II per Jackson et al. 2009) with greater than $50 \%$ contribution to external vertical work generated by the hindlimbs (Bundle and Dial 2003). 0.5bw and greater denote level 2 WAIR, equivalent to more mature Stage II and III individuals (per Jackson et al. 2009) which are capable of high angle to vertical ascents and whose forelimbs become more prominent in force production (Bundle and Dial 2003). Although we understand the transition between stages during WAIR is semi- 
301 artificial, we wished to create a classification scheme that corresponds to the different

302 levels of WAIR capabilities seen in extant systems (Dial and Jackson 2011). The

303 selection of $0.06 \mathrm{bw}$ for achieving stage I was chosen to represent real world recorded

304 minima for this behavior and thus should be considered minimal levels achieved before

305 reconstructions of WAIR are accepted.

306

307

\section{Coefficient of lift (Specific lift)}

308

309

310

311

312

313

314

315

316

317

318

319

320

321

322

323

We examined potential performance during the wing-driven phase of flap-running, WAIR, and leaping takeoff in our analyses. As a result, all three of the behaviors are subject to constraints of lift production efficiency. The production of lift relative to planform area, speed, and fluid density is summarized as the coefficient of lift. During WAIR analysis, a coefficient of lift (CL) of 1.0 was used. This corresponds to a value estimated during WAIR use in juvenile Chukars at early stage II (10 dph) (Heers et al. 2014) but greater than that in the earlier ontogenetic stages (Heers et al. 2011). We selected this value as this age class has been proposed to be analogous to derived maniraptoran theropod capabilities such as Anchiornis and Microraptor and this $\mathrm{Cl}$ is achievable by all ontogenetic stages beyond $5 \mathrm{dph}$ depending on the angle of attack (Heers et al. 2014). For leaping takeoff we used a Cl of 1.5, which corresponds to the minimal values estimated in adult Chukars during high angle WAIR (Heers et al. 2011) and below the 1.64 calculated for the pigeon during takeoff (Usherwood 2009). For flap running we used the equations of Burgers and Chiappe (1999) with the following modifications: we ran permutations for all three downstroke $\left(50^{\circ}, 70^{\circ}\right.$ and $\left.90^{\circ}\right)$ angles not just $50^{\circ}$ as per the original analysis and reduced the $\mathrm{Cl}$ to 1.2 from 2 . We 
324 choose to make the $\mathrm{Cl}$ closer to that estimated during late stage Chukar WAIR attempts 325 (Heers et al. 2011) as WAIR is simply a specific use case of flap running on a highly 326 angled substrate. This value is achievable by Chukars older than $20 \mathrm{dph}$ (Heers et al. 327 2014). Using the $\mathrm{Cl}$ of non-volant and juvenile Chukar both produces reasonable 328 minimum values for these behaviours and more closely simulates the expected outputs 329 in non-avian theropods before powered flight.

330 During low advance ratio wing-driven behaviors (launch, landing, WAIR, etc), the coefficient of drag can be quite large. In young Chukars, the coefficient of drag can be near the coefficient of lift, thereby potentially providing a significant component of weight support during controlled descent or significantly affecting reaction forces during WAIR (Heers et al., 2011). To confirm that using pure $\mathrm{Cl}$ as our specific fluid force coefficient was an accurate approach (instead of the total fluid resultant with both $\mathrm{Cl}$ and $\mathrm{Cd}$ ), we compared predicted reaction forces and weight support to values measured in vivo and reported in the literature (Tobalske and Dial 2007, Heers et al. 2014). Because a close match was found across multiple size classes, we assume for the remainder of the calculations that reaction forces during WAIR are not greatly affected by a high coefficient of drag (though we note that for controlled descent or burst climb out, behaviors we did not investigate, high $\mathrm{Cd}$ is likely a critical component).

\section{Wing beat frequency}

Wing beat frequencies scale negatively to body mass in steady flight (Greenewalt 1975; Pennycuick 2008) and takeoff (Askew et al. 2001; Jackson 2009) across species in extant birds. Wingbeat frequencies during takeoff are similar to those during WAIR (Tobalske and Dial 2007). For this study we used the maximum takeoff wingbeat 
347 frequency regressions from Jackson (2009) for all birds in his sample (ALL in

348 Supplemental Tables), and for only ground foraging birds (GF), we also added

349 Galliformes takeoff data from Askew et al. (2001) to Jackson's dataset to produce a

350 third regression equation (MOD). For the MOD dataset we incorporated a phylogenetic

351 correction using PDAP v 1.15 (Midford et al. 2010), with branch lengths based on

352 divergence times derived from the chronograms of Jetz et al. (Jetz et al. 2012) (Data 353 S2).

\section{Wing range of motion}

Abduction of the forelimb beyond the horizontal plane that transects the vertebral column was not possible in most non-avian theropods resulting in a maximum stroke angle for forelimb motion to be less than $90^{\circ}$ (Senter 2006a,b; Turner et al. 2012). The glenoid fossa faces ventrolaterally in these taxa and only shifted to a more lateral configuration at Paraves (Makovicky and Zanno 2011; Turner et al. 2012). The glenoid 360 continued to translate upward until reaching the dorsolaterally facing position of most extant birds at the phylogenetic level of Jeholornis and Sapeornis (Zhou and Zhang 362 2003a,b).

WAIR, the abductive flap angle of juvenile Chukars ranges from 90 degrees at stage I to 365 greater than $143^{\circ}$ at stage II (Jackson et al. 2009). Images show that in all cases, the forelimb ascends to a vertical or slightly beyond position (see Tobalske and Dial 2007 Figs 4,6; Jackson et al. 2009 Fig. 1; Heers et al. 2014 Fig. 1). angles of $50^{\circ}, 70^{\circ}$ and $90^{\circ}$ to encapsulate the range of values expected across 
370 Theropoda and ran them for all taxa. $90^{\circ}$ is likely unattainable for all non-avian

371 theropods due to the constraints of reducing contact with the substrate on the latter part

372 of the downstroke and shoulder morphology since the humerus cannot exceed the

373 dorsal rim of the glenoid which is aligned with the vertebral axis (or vertebral frame of

374 reference per Dial et al. 2008). It was included to create an upper bracket on possible

375 support values.

376

Velocities for the center of mass used for the different analyses were based on

377 those of extant birds. For WAIR used as our assigned velocity $1.5 \mathrm{~m} / \mathrm{s}$ based on the

378 speed of adult birds (Tobalske and Dial 2007). This is higher than achieved for the

379 early, pre-flight capable ontogenetic stages $(0.6 \mathrm{~m} / \mathrm{s}$ in stage $\mathrm{I}, 1.2 \mathrm{~m} / \mathrm{s}$ in stage II), and

380 thus acts as a fair upper velocity bound, though it is likely beyond the capabilities of

381 non-avian theropods with less developed wings. For leaping we calculated three values:

382 height gain if wing thrust was added to that generated by the hindlimbs, vertical distance

383 increase given the increased take off velocity due to flapping and takeoff potential from

384 a standing jump. Calculating height and distance gain was done through a modification

385 of existing equations used to model pterosaur launch (Witton and Habib 2010) to

386 account for the bipedal nature of non-avian theropods (see Supplementary Information

387 for these equations). To compensate for the effects of body size, a scalar is introduced

388 to ensure the pre-loading values would be 2.4 , a conservative value well within the

389 range seen in extant tetrapods (Biewener 2003). Our pre-loading scalar accounts for the

390 fact that animals gain significant power amplification from the release of stored elastic

391 energy in their limbs. Even in non-specialist jumpers this amplification can be greater

392 than twice the maximum mass specific power derived from the muscles and in specialist 
393 can be 10x higher or more (Henery et al. 2005 and references therein). For leaping

394 takeoff our starting inputs were two different takeoff speeds recorded in on extant 395 avians (Earls 2000; Tobalske and Dial 2000; Askew et al. 2001). Higher values for 396 leaping have been recorded in some mammals (Günther et al. 1991) and after several 397 wing beats in birds (Askew et al. 2001; Berg and Biewener 2010), thus these values 398 may not represent the maximal possible values for small theropods. For flap running the 399 assigned start value was $2 \mathrm{~m} / \mathrm{s}$, which is the same starting velocity used in Burgers and 400 Chiappe (1999). This speed is well within the range of sprint speeds of many lizards 401 (Huey 1982; Christian and Garland 1996; Irschick and Jayne 1999) and small mammals 402 (Iriarte-Díaz 2002), whereas many terrestrial birds can sustain this speed for over thirty 403 minutes (Gatesy and Biewener 1991; Gatesy 1999). These values are likely well below 404 the maximum sprint speed of these taxa (Sellers and Manning 2007) but allowed us to 405 determine if there was significant increase in speed using the wing generated thrust 406 alone.

407 408 We excluded the potential drag and damage caused by hindlimb feathers of 409 some paravians through contact with the substrate. At low hindlimb angles used during 410 the ascent of inclined surfaces (see the metatarsus during WAIR in Figure 1 from 411 Jackson et al. 2009) the distal limb feathers would have contacted the surface and 412 caused frictional drag, which would have reduced performance and damaged the 413 feathers (Dececchi and Larsson 2011). Although these variables may have evolved 414 throughout the transition from theropods into early birds, treating them as constants 
415 provided a "best case scenario" for non-avian theropods constraining the upper limits for 416 when these behaviours were possible.

417

418

419

420

421

422

423

424

425

426

427

428

429

430

431

432

433

434

435

436

437

\section{Wing contribution to leaping}

Three additional estimates for wing contributions to vertical leaping were made. The first estimates the percentage increase possible to the maximum leap through the addition of thrust generated by flapping. This calculation assumed the maximum wing output occurred at the top of the leap arch, and that the forces generated were directed vertically. This was done through a modification of the terrestrial launch methodology of Witton and Habib (2010, see Data S3) to accommodate bipedal theropod models with and without wing generated thrust. The difference between the maximum height gained with wing generated thrust was presented as a percentage increase (see Data S3, 4 for more detailed description of the equations used and a sample calculation spreadsheet). The second evaluates the horizontal distance extension to a leap through the addition of flapping generated thrust. This was calculated by using the speed at takeoff generated by the equations for bipedal launch (see Data S3, 4) at both 30 and $45^{\circ}$ launch angle. The later corresponds to the theoretical best angle for a projectile while the former more closely resembles the angle of take off measured in human and lizard leapers (Toro et al. 2004; Linthorne et al. 2005, Wakai and Linthorne. 2005). In both cases our models were treated as if there was no difference in takeoff and landing height, thus making the calculation of jump distance

$$
D_{\text {jump }}=\left(v^{2} \sin 2 \Theta\right) / g
$$


438 Where $v$ equals the takeoff velocity and $\Theta$ the angle of takeoff.

439

440 Vertical take offs were deemed possible when body weight (bw) support values were 441 equal to or greater than 1.0 using the speed and lift parameters mentioned above.

442

443

444

445

446

447

448

449

450

451

452

453

454

455

456

457

458

459

460

\section{RESULTS}

\section{Wing loading}

Increase in WAIR ability broadly corresponds to decreased wing loading in Chukars (Heers and Dial 2015), something noted in other galliform birds (Dial et al. 2011). Thus wing loading values may offer a rough comparison between non-avian theropod specimens and Chukars of a similar body mass. Among non-avian theropods, wing loading values ranged from $46 \mathrm{~N} / \mathrm{m}^{2}$ (Microraptor) to over $11000 \mathrm{~N} / \mathrm{m}^{2}$

(Sinosauropteryx). Of the thirty-four non-avian specimens included, only eight, representing five genera (all are deinonychosaurs) showed loading values less than that seen in 1-day-old Chukars $\left(170 \mathrm{~N} / \mathrm{m}^{2}\right)$, the highest values recorded across ontogeny. 1day-old Chukar chicks do not WAIR, can only surmount inclines of less then $48^{0}$ still performed asynchronous wing beats and their wings make prolonged contacts with the substrate in a crawling fashion (Jackson et al. 2009, Heers and Dial 2015). No nonparavian showed values less than the $160 \mathrm{~N} / \mathrm{m}^{2}$ measured at $3 \mathrm{dph}$ Chukars, with most pennaraptorans at values 2-8 times that seen at even the highest Chukar chick loadings (Table 1, Figure 1). Focusing on the embryonic and early ontogenetic stage specimens in our analysis, to test whether WAIR was possible at early ages and lost through ontogeny, we recovered loading values again significantly higher than the highest 
461 values seen during Chukar ontogeny, with values $126 \%-234 \%$ those of 1 -day-old chicks 462 which were also significantly smaller. For comparison, the hatchling size

463 Similicaudipteryx specimen (STM 4-1) had a body mass estimated at approximately $46463 \mathrm{~g}$, similar to a $17 \mathrm{dph}$ Chukar chick (stage II), but wing loading values of $372 \mathrm{~N} / \mathrm{m}^{2}, 5.8$ 465 times higher than seen in the $17 \mathrm{dph}$ chick and over twice that seen in $3 \mathrm{dph}$ Chukars 466 due to Similicaudipteryx having a wing area only the size of a 6 dph chick which weight 467 approximately $16 \mathrm{~g}$. This suggests that none of the non-paravian theropods could 468 perform the lowest levels of WAIR, even disregarding their limited range of motion and 469 flapping frequency compared to juvenile extant avians. None of the Mesozoic avian 470 taxa, under either mass reconstruction, showed loading values above $74 \mathrm{~N} / \mathrm{m}^{2}$, which 471 corresponds to approximately $11 \mathrm{dph}$ (stage II) Chukar chicks, which is approximately 472 the time where fledgling begins (Harper et al. 1958, Christian 1996).

473

474 475 476

477 478 479 480 481 482 483

\section{WAIR}

At a CoM velocity of $1.5 \mathrm{~m} / \mathrm{s}$ nine of thirty-four specimens of non-avian theropods reached the minimal benchmark for level 1 WAIR $(0.06 \mathrm{bw})$ under at least one of the three flapping speed and flap angle permutations (Figure 2, Table 3, S4-6). When the velocity was decreased to $0.6 \mathrm{~m} / \mathrm{s}$ number that succeed decreased to eight as the Sinornithosaurus specimen based on the measurements of Sullivan et al (2010) failed to achieve the $0.06 \mathrm{bw}$ benchmark (Figure 2, Table 3). All are deinonychosaurs. Three specimens (the larger Similicaudipteryx specimen, and the smaller mass estimates for Yixianosaurus and Yulong) approach the WAIR level 1 criteria, but none yield values higher than $0.05 \mathrm{bw}$, and this only under the MOD reconstruction at the highest abduction angle. All specimens of Microraptor and the smaller specimens of Anchiornis 
484 and Eosinopteryx yielded bodyweight support values above $0.06 \mathrm{bw}$ across all 485 permutations at $1.5 \mathrm{~m} / \mathrm{s}$ whereas at $0.6 \mathrm{~m} / \mathrm{s}$ only the smaller Anchiornis and Microraptor 486 gui specimens achieve this. Within non-avian theropods using a $90^{\circ}$ flap angle at $4871.5 \mathrm{~m} / \mathrm{s}$, only a single specimen of Microraptor gui (BMNHC PH881) has body weight 488 support values reaching the $0.5 \mathrm{bw}$ cutoffs for WAIR level 2 , though the larger specimen 489 (IVPP V 13352) comes close under the MOD reconstruction (Table 3, S4-6). At $50^{\circ}$ only 490 the smaller Anchiornis, Changyuraptor, Eosinopteryx and all 3 Microraptor specimens, achieve the $0.06 \mathrm{bw}$ benchmark at $1.5 \mathrm{~m} / \mathrm{s}$ and this decreases to only the smaller 492 Anchiornis and Microraptor at $0.6 \mathrm{~m} / \mathrm{s}$. No non-avians or Archaeopteryx achieved bw 493 support values higher than 0.33 under the $50^{\circ}$ at $1.5 \mathrm{~m} / \mathrm{s}$ and only Microraptor gui, Archaeopteryx specimens and the smaller Anchiornis reaching a minimal of $0.1 \mathrm{bw}$ under this permutation.

Among Mesozoic birds, the different mass estimation methods produced significantly different body weight support values and are more prominent in the most basal birds in our analysis Sapeornis and Jeholornis. (Figure 2, Tables S4-6). All basal avians show the capability of level 1 WAIR (bw support values of 0.06 or greater) under all flap frequencies estimates, mass estimates or flap angles used here and no avians 502 showing values below $0.1 \mathrm{bw}$ under any permutation. In Archaeopteryx, there is no clear trend in WAIR capability and allometry as all specimens besides the Eichstatt individual 504 show a similar range of body weight support values (Table 3). At the higher flap angle 505 and lower mass, all avians show the capability for level 2 WAIR ( $>0.5 \mathrm{bw})$. All birds more 506 derived than Archaeopteryx yield a body weight support values in excess of $1.0 \mathrm{bw}$ at 
507 their lower mass estimate at $1.5 \mathrm{~m} / \mathrm{s} 90^{\circ}$ flap angle under all 3 flap frequencies, except

508 for Sapeornis where the smaller specimen exceeds $1.0 \mathrm{bw}$ only under the MOD

509 permutation. Of note, the values recovered for more derived avians are significantly

510 higher than those observed in experimental data (Tobalske and Dial 2007) or calculated

511 using extant measurements (Table 2, Table S7) and well above the 1.0 threshold for

512 take off. This suggests that these taxa could have performed this behavior at lower wing

513 beat frequencies, body velocities and flap angles than the values used here, as seen in

514 some extant birds (Jackson et al. 2011), or that physiology and power production

515 differed between extant and basal birds (Erickson et al. 2009, O'connor and Zhou

516 2015), or a combination of both. If the latter is correct, it suggests our measurements for

517 non-avian theropods overestimate the power production potential in these taxa, and

518 thus overestimate their WAIR capabilities.

519

\section{Flap running}

520

Among non-avian theropods, flap running peaked in effectiveness within small-bodied

521 paravians (Figures 3 Table S8). With a $90^{\circ}$ flap angle, the smaller Anchiornis specimen

522 and Microraptor gui were the only non-avian taxa to show increases greater than 1.0 523 $\mathrm{m} / \mathrm{s}$ under all permutations (71-79\% and $75-208 \%$ performance increases, respectively),

524 although only Microraptor achieved speeds capable of flight. More realistic $50^{\circ}$ flap 525 angles yielded only a $23-27 \%$ and $26-65 \%$ performance increase for these taxa. Among 526 non-paravians, even under the highest flap angle and flap frequency permutations no

527 taxon exceeded an increase of $17 \%$ in running speed with the highest values found in

528 the larger specimen of Similicaudipteryx. At flap angles below $90^{\circ}$ only the larger

529 Similicaudipteryx and the lighter mass estimated Yixianosaurus specimens among non- 
530 paravians yielded velocity increases approaching 10\%. Although some paravians had

531 high levels of increased speed, Mahakala, Mei, Jinfengopteryx, Xiaotingia, Tianyuraptor,

532 and Sinovenator showed increases of less $17 \%$ under all permutations, with many

533 showing values in the single digits. At $50^{\circ}$ only Microraptor sp., Changyuraptor,

534 Eosinopteryx and Anchiornis showed a greater than $10 \%$ increase in running velocity.

535 All specimens of Archaeopteryx showed speed increases similar to or greater than

536 those seen in Microraptor and Anchiornis though there is no clear pattern relating body

537 size to speed, as the largest (London) and smallest (Eichstatt) specimens yielded

538 similar values (Table S8). Only Microraptor and all specimens of Archaeopteryx showed

539 the ability to achieve takeoff velocities by this method alone (Table S8).

540

541

\section{Leaping}

542 The use of forelimbs during jumping was divided into three discrete analyses, one

543 examining the potential of the wings to increase maximum jump height, one to examine

544 distance gained horizontally, and finally to see if the wings could generate enough force

545 to take off from a standing start as seen in most extant birds.

546

547

\section{Vertical}

548 No non-paravian gained more than $8 \%$ additional height with flapping using the highest

549 flap angles, and most gained less than 3\% (Figure 3, Table S9). Using more reasonable

550 flap angles of $50^{\circ}$, none exceeded $4 \%$. Within paravians, several taxa generated greater

551 than $10 \%$ height increases, including Anchiornis, Microraptor, Eosinopteryx,

552 Changyuraptor, Aurornis and all Archaeopteryx specimens (Table S9). Despite this 
553 most troodontids, both the "short armed" Jehol Dromaeosaurs, Mahakala and

554 Sinornithosaurus showed values more similar to non-paravians, between 1-8.5\%

555 increase in height. Of interest, the "four winged" taxa used here (Anchiornis,

556 Microraptor, and Changyuraptor) yielded increased height gains on the order of 16-

$55764 \%$, with Microraptor gui specimens showing values in excess of $50 \%$ (Figure 3, Table

558 S9). Even under the lowest flap angle settings, both specimens of $M$. gui showed 559 leaping height increases of greater than $30 \%$, almost four times the value for the non-

560 paravians under any setting, and Changyuraptor and Microraptor hanqingi showed

561 values of approximately $20 \%$, which is greater than twice the highest value seen in any

562 non-paravian. All Archaeopteryx specimens showed height gains greater than $30 \%$

563 under all mass permutations, with the lighter estimates for the Berlin, Thermopolis and

$56411^{\text {th }}$ specimen exceeding $190 \%$ non-flapping height values. Interestingly the only

565 specimen that did not reach the $50 \%$ height gain under any permutation is the Eichstatt

566 specimen, the smallest in our analysis, whose range between $34-48 \%$ gain is similar to

567 what is seen in the larger microraptorine specimens (excluding Sinornithosaurus).

568

569

\section{Horizontal}

570 Similar to vertical leaping, there was a marked disparity between distance gained in the

571 "four winged" paravian taxa and all others (Table S10). Only one non-paravian

572 Similicaudipteryx STM-22, under the highest setting and at a $45^{\circ}$ takeoff angle, showed

573 distance increases of $5 \%$ or greater. Among paravians Microraptor, Changyuraptor, the

574 smaller Anchiornis and all species of Archaeopteryx show leaping values greater than 
$57520 \%$ non-flapping horizontal distance at the $45^{0}$ take off, though this drops to $15 \%$ at $57630^{\circ}$.

577

578

\section{Vertical takeoff}

579 Among non-avians, only Microraptor gui achieved body weight supports greater 580 than 1 under any flap angle or flapping frequency permutation under the two avian 581 derived take off speeds assessed. No non-paravian showed values greater than $0.15 \mathrm{bw}$ 582 under these conditions (Tables S11-13). Outside of Microraptor, Changyuraptor and the 583 smaller specimen of Anchiornis, deinonychosaurians did not have values beyond $0.5 \mathrm{bw}$ 584 under either speed or any flap frequency permutation. In avians at the lower body 585 weight estimate, all taxa showed values greater than $1.0 \mathrm{bw}$ at the high end of their 586 flapping angle range. At the higher mass estimates, multiple specimens of Archaeopteryx showed levels below $1.0 \mathrm{bw}$, with the lowest values seen in the Eichstatt and London specimens (Tables S11-13). Many extant avians use launch speeds between $1.5 \mathrm{~m} / \mathrm{s}$ and 3.8m/s (Earls 2000, Berg and Biewener 2010, Heers et al. 2014). At these takeoff speed avians more derived that Archaeopteryx achieved values in excess of $1.0 \mathrm{bw}$, with the exception of the larger mass estimates of Sapeornis under the ALL and GF flapping estimates (Tables S4-6, S11-13). At the higher speed of $5.1 \mathrm{~m} / \mathrm{s}$, 593 achievable by strong leapers, beyond Microraptor the only other non-avian theropods to 594 achieve greater than 1.0bw support was the smaller specimen of Anchiornis under a 595 single flap rate permutation at $90^{\circ}$ flap angle. 596

\section{DISCUSSION}


A major challenge of attempting to create models that examine evolutionary

599 transitions is that of efficiency versus effectiveness. Evolved traits may need to only

600 function at some basic level, rather than contribute high degrees of functional

601 adaptation. Thus an argument against our use of thresholds, such as a $6 \%$ body weight

602 support as the minimum for WAIR, is that smaller values, such as $5 \%$ or even $1 \%$, may

603 still provide selective advantages for individuals. Although this line of thought is

604 defensible, we suggest a challenge to this. The first is that these low values are not

605 testable in the sense that there are not physically defined thresholds to demarcate when

606 a behaviour may or may not function. Without these parameters to test, any discussion

607 becomes a story-telling scenario. In addition, we have used liberal parameters in

608 reconstructing extinct taxa based on output values measured in modern, derived avians.

609 This optimistic reconstruction of the possible ignores that non-avian theropods have

610 additional functional restrictions based in their musculoskeletal, neuromuscular and

611 integumentary systems not present in extant birds. The minimal age of origin for

612 powered flight in avian theropods where is 130 million years ago (Wang et al. 2015) and

613 this behavior and all its functional and morphological components have been under

614 refinement through selection ever since. Thus we postulate that the claim that non-avian

615 theropod would be able to perform functions at output levels below the threshold

616 minimums seen in extant avian taxa difficult to defend. For example, flapping frequency

617 and flap angle have large effects on the resulting body weight support values and using

618 avian take off values are likely significant over estimations for values obtainable in most

619 if not all the taxa sampled here. Our use of a velocity of $1.5 \mathrm{~m} / \mathrm{s}$ is based on the speed

620 of adult Chukars, whose WAIR ability is much greater than proposed of any non-avian 
621 taxa examined here. Using juvenile values $(0.6 \mathrm{~m} / \mathrm{s}$ of stage I) reduces the bw support

622 values by approximately one third. Additionally, by using coefficient of lift values of 1 ,

623 which is higher than is seen in a 20 dph Chukar at 45-degree angle of attack (stage II

624 per Jackson et al. 2009), we are likely highly positively biasing the results. Thus we

625 argue that due to our relaxed constraints and the significantly higher wing loadings to

626 that seen in any stage of Chukar development (even the asymmetrical crawling stage of

627 1-3d ph from Jackson et al. 2009), the taxa sampled here that did not reach the 0.06bw

628 threshold derived from in vivo experiments or meet the wing loading values seen in the

629 earliest stages of ontogeny should not be considered WAIR capable. Although we do

630 not have in vivo derived values to compare with leaping and flap running estimates, it is

631 not parsimonious to propose that small incremental increases measured only under

632 unnaturally lenient conditions support a behavior.

633

634 For all behaviours tested here there is a sharp contrast in performance levels between a

635 small number of paravian taxa (Microraptor, Anchiornis, Changyuraptor, Aurornis and

636 Eosinopteryx) and all other non-avian taxa. This discrepancy is marked not only

637 because it does not correlate to the origin of pennaceous feathers at pennaraptora but it

638 also does not include all members of Paraves within the high performing category.

639 Multiple small bodied and basal members of both deinonychosaurian subgroups, such

640 as Mahakala, Xiaotingia, Jinfengopteryx, Mei, Sinovenator and Sinornithosaurus, show

641 little evidence of benefit from flapping assisted locomotion. As these taxa are similar in

642 size to the paravians that do show potential benefits, the argument that this loss is a

643 byproduct of allometry is not possible. Allometric loss of performance is possible though 
644 in the larger, feathered dromaeosaurs like Velociraptor ( 15 kg, Turner et al. 2007) or

645 Dakotaraptor ( 350 kg, Depalma et al. 2015), but our data from embryonic

646 maniraptorans does not support this postulate. As our measurements for the small

647 paravian wing areas are based either on preserved feather length (Sinornithosaurus) or

648 on long feathered close relatives (Anchiornis for Xiaotingia, Jinfengopteryx, Mei,

649 Sinovenator and Microraptor for Mahakala) our values for them are likely overestimates

650 and suggests that locomotion was not a major driver for forelimb evolution, even among

651 small sized paravians.

652

653

Flap Running

654 There are questions as to whether a flap running model is particularly efficient for any

655 taxa. One immediate set of constraints relates to performance of the hind limb under a

656 potential flap-running model. The thrust production model we used assumes the

657 hindlimb and forelimb propulsion potentials were simply additive. However, in reality the

658 hindlimb performance must have some maximum output that is likely to be exceeded if

659 the forelimbs produce significant additional propulsive force. Thus at high wing-

660 produced thrust production, the hindlimbs likely cannot move fast enough to

661 accommodate the faster speeds. Under such conditions, an animal would pitch forward 662 and fall.

663 We also assume that most of the lift produced by the wings during flap-running

664 could be oriented as thrust. The proportion of force that can be oriented as thrust is,

665 however, constrained by wing kinematics, particularly the amount of spanwise twist that

666 the wing can undergo during the flight stroke (losilevskii 2014). Thus our thrust 
667 proportions for theropods may be unrealistically high, overestimating the speed 668 generated.

669

670 Additionally, downstroke lift production not reoriented as thrust would act to 671 displace some weight. Although this is important and necessary in flight, it would reduce 672 hindlimb performance during flap-running by reducing the normal force acting through 673 the feet. A similar phenomena occurs during high angled WAIR (Bundle and Dial 2003).

674 Finally, the production of lift during flap-running, regardless of orientation relative to 675 travel, would generate significant amounts of drag (including profile drag, pressure drag, 676 and induced drag). Given these potential performance constraints, it is questionable 677 whether flap-running would be as effective a locomotion mode as our data suggests, 678 even for taxa like Microraptor.

679

680

\section{WAIR}

681

682

The finding that not a single non-paravian reaches the $6 \%$ bodyweight threshold 683 for level 1 WAIR challenges the proposal that WAIR offers a behavioural pathway for 684 basal maniraptorans (Dial 2006, Heers et al. 2011, 2014). The few cases that approach 685 these values (Similicaudipteryx, Yulong, and Yixianosaurus) are only achieved under wing angle and wing beat permutations that are unrealistic given their pectoral

687 musculoskeletal structures (Baier et al. 2007; Turner et al. 2012). MOD derived wing 688 beat values in beats per second for the larger Similicaudipteryx ( $6 \mathrm{hz})$, Yixianosaurus 689 (7-8 hz), Yulong (10 hz) are greater than or equal to those of smaller extant birds such 
690 as the Magpie (Pica pica) (9.2 hz), Crow (Corvus brachyrhynchos) (6.6 hz) and Raven 691 (Corvus corvax) (6.1 hz) (Jackson 2009) and are so elevated due to the inclusion in that 692 dataset of galliform birds, which are short burst specialists with shortened wings, large 693 pectoralis and supracoracoideus muscle masses and muscle fiber adaptations to 694 maximize their flight style (Askew and Marsh 2001; Tobalske et al. 2003). These 695 specialized muscles are adapted to allow wing beat frequencies beyond those of other 696 birds at a similar body mass (Tobalske and Dial 2000, 2007; Jackson 2009; Jackson et 697 al. 2009) thus inflating our wing beat frequency estimates. Wing beat frequencies were 698 likely much lower in non-avian theropods than in modern birds during takeoff, which is 699 higher than during level flight (Dial 1992, Berg and Biewener 2013), given the relatively 700 small size of their wing musculature and plesiomorphic musculoskeletal anatomy 701 (Jasinoski et al. 2006; Allen et al. 2013; Baier et al. 2007; Bock 2013; Burch 2014). 702

703 In none of our nine permutations did values indicating level 1 WAIR performances 704 become unambiguously optimized at Paraves (Data S1). This is despite our 705 conservative application of constraints such as use of a $90^{\circ}$ flap angle, flap frequencies 706 comparable of greater than many extant avians, WAIR velocity comparable to adult

707 Chukars and generous wing area estimates. In paravians that do shown positive scores 708 these are no more than $0.12 \mathrm{bw}$ under $90^{\circ}$ flap angle at a velocity of $1.5 \mathrm{~m} / \mathrm{s}$ and any 709 flapping frequency reconstruction for the larger Anchiornis, Aurornis, Eosinopteryx or 710 Sinornithosaurus and Changyuraptor under all but the MOD flapping rate estimate

711 (Table 3). This suggests that tightening these constraints either singularly or 712 combination would likely exclude marginally performing taxa from even this threshold. 
713 For example using the body velocity of $6-8 \mathrm{dph}$ Chukars $(0.6 \mathrm{~m} / \mathrm{s})$ at $70^{\circ} \mathrm{flap}$ angle,

714 excludes Aurornis, the larger Anchiornis, Eosinopteryx under all permutations and

715 Changyuraptor except under the MOD flapping frequency.

716

717 Given the low values seen Aurornis and reduced flapping ability in Eosinopteryx

718 (Godefroit et al. 2013) it is likely that only the juvenile Anchiornis specimen, Microraptor

719 and Changyuraptor among non-avian theropods would even have the potential to use

720 this behavior. When we introduce other factors in addition to those listed above such as

721 the symmetrical feathers or the plesiomorphic pectoral girdle would likely have limited

722 the prevalence of WAIR further, if present at all, to only the microraptorines as they

723 would have further reduce the effectiveness of the wings in force generation. Feather

724 asymmetry aids in resisting out of plane forces and is crucial for their bending and

725 twisting during the flight stroke (Ennos et al. 1995; Norberg 2002). While the pectoral

726 girdle morphology of Anchiornis which show non-elongated and convex coracoid and

727 lack of ossified sternum or fused gastralia, denote reduced pectoral muscle mass

728 compared to microraptorines (Zheng et al. 2014). This does not make a strong case that

729 this behavior was present ancestrally in Paravians, yet alone that it coincided with

730 pennaceous feather evolution and elongation (present at Pennaraptora) or other flight

731 related adaptations. Our findings suggest that if present at all, there is a minimum of two

732 origins for the use of flap-based locomotion with the presently accepted phylogenetic

733 hypotheses; once within microraptorines, and once in Aves. This is not completely

734 surprising as other traits related to flight, such as an alula, elongated coracoid, and a

735 broad, ossified single sternum plate, are also independently derived in Microraptor and 
736 basal avians that are more derived than Sapeornis, suggesting convergent evolution in

737 early powered flight (Zheng et al. 2014).

738

739 To compare the results of our body mass and wing area estimates to others in

740 the literature we ran the WAIR and leaping takeoff analyses using previously published

741 mass and wing area values for Archaeopteryx (Yalden 1984), Microraptor (Chatterjee

742 and Templin 2007; Alexander et al. 2010), Caudipteryx and Protarchaeopteryx (Nudds

743 and Dyke 2009). In all cases, WAIR values were similar, often below, values calculated

744 in our analysis (Table S14). Non-paravians yielded WAIR values near Obw and take off

745 speeds were required to be greater than $46 \mathrm{~m} / \mathrm{s}$. Microraptor specimens showed takeoff

746 velocities between $4.1-6.6 \mathrm{~m} / \mathrm{s}$, values achievable either by running or leaping

747 methods and similar to those estimated in our original analysis.

748

749

\section{Locomotory pathways to flight: necessity or red herring?}

750

Our first principles modeling approach, which accurately predicts WAIR values

751 for Chukar chicks, supports the postulate that for these "near flight" behaviors, wing

752 area is the major determinant of function rather than power. One potential argument for

753 why a locomotory pathway is required for the evolution of flight related characters is that

754 the muscle hypertrophy in the pectoral girdle present in extant flying birds would be

755 unlikely to have evolved passively if display or stability flapping methods drove the

756 origin of large wings. Although it is undeniable that extant avians have proportionally

757 and significantly more wing musculature than non-avian theropods, the minimum level

758 needed to achieve a ground-based takeoff is unknown. There are several volant birds 
759 with flight muscle ratios (flight muscle mass proportion of total mass) below $16 \%$

760 (Marden 1987). Juvenile Chukars that fledge less than two weeks after hatching (Harper

761 et al. 1958; Christiansen 1970, 1996) and young peafowl (which fledge after one to two

762 weeks Fowler 2011) also have ratios below this value. Recent estimates for Microraptor 763 yield values within this range (Allen et al. 2013).

764

765

Fledging aged Chukars and Peafowl have a reduced flight muscle fraction

766

767

768

769

770

771

772

773

774

775

776

777

778

779

780

781

compared to adult birds. In Chukar's, at $14-15 \mathrm{dph}$, the pectoral mass is only $48-62 \%$ the relative size (as a proportion of total mass) compared to adult birds, while in Peafowl (12 dph) this range is between $38-45 \%$ (Heers et al. 2015). Yet at this age the wing loading values are significantly less than in adults, with 15 dph Chukars showing values only $38 \%$ of adults and $11-14$ dph Peafowl showing values ranging from $22-25 \%$ of those seen in adults. Among non-avian theropods only Microraptor (specimens BMNHC PH 881, IVPP V 13352, LVH 0026 under Alexander et al. 2010's mass estimate) and the juvenile Anchiornis (BMNHCPH828) have similar wing loading values to fledging aged Chukar (10-17 dph) (Heers et al. 2015). Of these only Microraptor and early avians have previously been suggested to have similar pectoral muscle mass fractions (pectoral limbs region $13-15 \%$ of total mass per Allen et al. 2013) combined with similar wing loading values as seen in volant juvenile Chukars (minimum forelimb muscle mass of $14 \%$ of body mass, wing loading values below $80 \mathrm{~N} / \mathrm{m}^{2}$ ). Thus we contend that these taxa may have had a power output that would be capable of ground based take off, as the reduced pectoral musculature was compensated for by their large wing size. 
Even at slight lower estimates of flight muscle mass percentage take off may be

783

784

785

786

787

788

789

790

791

792

793

794

795

796

797

798

799

800

801

802

803

804

possible in Microraptor and basal avians. Early fledgling aged Chukar chicks show

forelimb muscle mass fractions (Heers and Dial 2015) below the $16 \%$ suggested as the minimum for take off by Marden (1987). This is due to their proportionally large wings.

With such proportionally large wing area even at low forelimb mass fledging aged

Chukars can that generate lift values estimated at between $10.4-12.2 \mathrm{~N} / \mathrm{kg}$ of body

mass (using the muscle-specific power output value of $360 \mathrm{~W} / \mathrm{kg}$ per Askew et al. 2001)

which exceeds the minimum needed for takeoff $(9.8 \mathrm{~N} / \mathrm{kg}$ ) (Marden 1994). Therefore if

wing area can partially overcome the need for significant muscle mass fractions

arguments on the need for a selective pathway to muscle hypertrophy need not be

invoked when discussing the origins of flight. This would also help explain the lack of features indicating significant hypertrophy in pectoral musculature, such as a lack of a

sternal plate, in the earliest fliers (Zheng et al. 2014) and the delayed presence of a keel until Ornithothoraces (O'Connor et al. 2015). These findings suggest that powered flight originated before pronounced muscle hypertrophy and likely depended more on wing loading and shoulder mobility. Thus the pathway to large pectoral muscles is one that occurred within Aves, not before and likely is linked to the refinement and extension of level flight capabilities.

For WAIR, a similar trade off between muscle mass and wing area likely exists. In juvenile galliforms, flight muscle mass increases logistically throughout ontogeny. In Chukars this goes from about $2 \%$ in crawling, non-WAIR capable $3 \mathrm{dph}$ juveniles to 26 $29 \%$ in $100+d p h$ adults (Heers and Dial. 2015). Individuals capable of stage I WAIR 
805 (8dph, maximum WAIR angle $65^{\circ}$ ) have proportional muscle masses between $7.5-9.9 \%$ 806 of body mass, which represents $25-40 \%$ of adult proportional pectoral mass values 807 (Heers and Dial 2015). They also show wing loading values only $55-60 \%$ those of an 808 adult, which should be noted can achieve much larger maximum WAIR angles $\left(>90^{\circ}\right)$. A 809 similar pattern is seen in both late Stage II WAIR Chukars and in juvenile Peafowl. The 810 former can ascend up to $85^{\circ}$ despite showing reduced pectoral muscle mass relative to 811 bodymass (48-62\% adult values) but have wing loading values only $40 \%$ those of adult

812 birds. Juvenile peafowl, which at $12 \mathrm{dph}$ can achieve higher WAIR angles than adults, 813 display less than half the relative pectoral muscle mass fraction of adults, but have 814 wing loading value of only $1 / 4$ to $1 / 3$ that seen in adults (Heers and Dial 2015). This 815 suggests that reducing wing loading could partially compensate for the lower 816 proportional muscle mass, an idea that is also supported by findings in Brush Turkeys 817 where low wing loaded juveniles can WAIR whereas adults cannot (Dial and Jackson 818 2011).

819 We generated a model for Chukar WAIR ontogeny that predicts wing loading, 820 pectoral mass, maximum WAIR angle, and age using data from Heers and Dial (2015) 821 (Figure 4). Most relationships are nonlinear and multimodal, suggesting complex 822 interactions between these factors. The original and modeled data show an inflection 823 point between $20-30 \mathrm{dph}$. Up to this age, maximum WAIR angle asymptotes at less 824 than 90 degrees (Jackson et al. 2009; Heers and Dial 2015). This corresponds to when 825 the pectoral muscles reaches $\sim 20 \%$ total body mass and the beginning of Stage III 826 where both extended level flight and vertical flight is possible (Jackson et al. 2009). 827 Here is also when we begin to see, through in vivo measurements, the steady increase 
828 in wing loading values from their minimum of $55 \mathrm{~N} / \mathrm{m}^{2}$ at day 22 continuing upwards to

829 the full term $(100+d p h)$ score of $161 \mathrm{~N} / \mathrm{m}^{2}$.

830

831

Early stage Chukar chicks have forelimb masses within the range suspected for

832

non-avian theropods (up to $15 \mathrm{dph}$ ) and we see a correlation among these chicks

833 between maximum WAIR angle and lower wing loading (Figure 4, 5). WAIR capable

834 Chukar chicks during this period, which corresponds to late Stage I through Stage II of

835 Jackson et al. (2009), show relatively constant wing beat frequencies (22-26hz) and flap angles $\left(\sim 140^{\circ}\right)$ further supporting the idea that wing loading is a major factor influencing maximum WAIR angle. Wing loading values in WAIR capable galliforms are significantly below that seen in much of our dataset and only eight specimens, pertaining to five paravian taxa show wing loading values below $200 \mathrm{~N} / \mathrm{m}^{2}$ (Table 1, Figure 5). Of these only Microraptor, a juvenile Anchiornis, and Eosinopteryx show wing loadings that,

841 according to this model, suggest WAIR is even possible. Given that the flapping

842 frequencies and stoke angles under those seen in the extant Chukars for which this 843 relationship between this compensatory mechanism for low muscle mass occurs, the 844 levels they achieve are likely beyond non-avian theropods. This suggests that this 845 compensatory pathway would likely be less efficient or even unavailable to most non846 avian theropods, again likely restricting WAIR potential to only the microraptorines.

849 for Chukar chicks, supports the postulate that for these "near flight" behaviors, wing 850 area is the major determinant of function rather than power. Many possible selective 
851 regimes can be put forward for driving the expansion of wing area before it would

852 provide any locomotory benefit. These include display (Hopp and Orsen 2004;

853 Zelenitsky et al. 2012), egg shielding (Carey and Adams 2001), braking, or balance

854 (Fowler et al. 2011), and our results suggest that they need to be investigated in greater

855 detail in order to understand the drivers for major pre-requisites for the flight stroke and

856 reduced wing loading. The flight stroke itself, once we have divorced it from the early

857 expansion of the wing and the origin of pennaceous feathers likely occurred after

858 expansion into the wing-loading region where wing based locomotory regimes are

859 possible. Thereafter multiple possible scenarios can be sought to explain the origin of

860 flight stroke and flight itself, with potentially different scenarios occurring in different

861 lineages.. Our data indicates that whichever scenario, WAIR would be restricted in its

862 functional presence to, at the earliest, small-bodied Paraves or more likely the base of

863 Aves; well after previous suggestions (Heers and Dial 2012).

864

865

\section{Ontogenetic versus phylogenetic signals}

866 The findings of our model that all non-paravian theropods and most deinonychosaurians

867 were incapable of using WAIR, raises the question of when along the lineage could

868 WAIR have evolved and under what selective context? As our data shows there is no

869 evidence of WAIR in non-paravian theropods, this challenges the hypothesis that

870 modern bird ontogeny recapitulates the pathway to the origin of flight. Although it is

871 tempting to suppose that behaviours young, non-volant extant birds undertake can offer

872 some insight into the origins of flight, modern bird chicks do not present plesiomorphic

873 morphologies. Although extant birds hatch with somewhat reduced forelimb muscle

874 masses and feathering, the musculoskeletal morphology is still generally comparable 
875 with adult extant fliers. For example, near-hatchling quail embryos do not have an 876 ossified sternal keel, but instead have a cartilaginous or connective tissue based on

877 (Menleey et al. 1989; Tahara and Larsson 2013 Fig 5). Some birds, such as chickens, 878 which are bred for greatly enlarged pectoral muscles, do develop a broad sternum with 879 a robust midline keel in ovo (Hall and Herring 1990). In most non-avian theropods, 880 including many small paravians, the sternum is either composed of a pair of unfused 881 plates or completely absent (Xu et al. 1999; Hwang et al. 2002; Gong et al. 2012;

882 Godefroit et al. 2012; Zheng et al. 2014; Lu and Brusatte 2015) with the notable 883 exception of Microraptor gui (Xu et al. 2003), thus it is unlikely to have even a 884 cartilaginous or rudimentary keel seen in juvenile birds. Beyond this the oblique 885 acrocoracohumeral ligament orientation and triosseal canal and a dorsally oriented 886 glenoid fossa are also present in extant avian embryos, even in poor fliers like Chukars, 887 but not in non-avian theropods. These differences combined with those in muscle mass 888 and neuromuscular pathways differentiate the ontogentic transitions of juvenile birds 889 from evolutionary ones regarding avian origins. This is especially true as the exemplar 890 non-avian theropod taxa (Dial 2006, Heers and Dial 2012, 2015) do not represent an 891 anagenic sequence but are instead derived members of lineages separated by tens of 892 millions of years.

893 steaming in pre-fledgling ducklings (Aigeldinger and Fish 1995), begging and signaling 896 in altricial chicks (Rydén and Bengtsson 1980; Glassey and Forbes 2002; Ngoenjun et 897 al. 2009), and social displays and thermoregulation in Ostriches (Bolwig 1973; Mushi et 898 al. 2008). This indicates that even in the most basal lineage of extant avians, the 
899 ancestral flight stroke has been modified by juvenile and non-volant individuals to 900 perform other tasks. Even late stage avian embryos and wingless hatchlings perform 901 coordinated flapping motions on their own and when stimulated (Hamburger and 902 Oppenheim 1967; Provine 1979, 1981a,b, 1982) showing that the neurological pathway 903 for flapping motion is active and functioning before hatching in precocial birds (Provine 904 1979). These embryonically established neural controls are thus available to the earliest 905 hatchlings of modern birds (volant or not) but non-avian theropods may not have had 906 neuromuscular control or the coordinated flapping behaviours even extant chicks do.

907 Although ontogenetic trajectories are relatively linear, with regards to a species, 908 phylogenetic trajectories are not. The WAIR capabilities of extant birds may be a direct result of their advanced powered flight adaptations rather than a precursor for it.

Because the factors that facilitate WAIR are the same as those that permit flight

911 (increased wing area, muscle resources, and flapping arc), WAIR may be more of a 912 spandrel that extant birds have capitalized on rather than a selective pathway. Thus we

913 propose instead that juvenile birds exapted the flight stroke for use as an escape 914 technique before they were capable of takeoff and flight, and this derived escape 915 response was only possible once the complex flight adaptations of derived birds 916 evolved. Although no thrust based locomotory method succeeded in providing an 920 adequate evolutionary pathway with an obvious evolutionary trend that surpassed 921 biophysical thresholds, some individual specimens did succeed at crossing these 
922 thresholds under certain parameters. Notably Microraptor gui and Archaeopteryx 923 showed significant results in all three methods. Interestingly, both taxa were estimated 924 to have had the potential for ground based takeoff at both sprint speeds and leaping 925 takeoff values (Tables S8, 11-13). Given the effects of flap running's thrust generation 926 (though see potential limitations below), takeoff speeds can be achieved with a starting 927 velocity well within the range of similar sized extant tetrapods. Even a sprint speed, 928 without wing assistance, of $7 \mathrm{~m} / \mathrm{s}$ is not unrealistic given greater speeds are obtained by 929 the Roadrunner (Lockwood 2010), Red legged Seriemas (Abourachid et al. 2005), 930 multiple small mammals (Iriarte-Díaz 2002), and some lizards (Huey 1982; Clemente et al. 2009). Living birds that launch by running are overwhelmingly aquatic or semi-aquatic taxa, suggesting that running takeoff is mostly an adaptation to compliant surfaces. (as

934 referenced in Earls 2000). Other birds utilize a leaping takeoff to initiate flight with high 935 instantaneous speeds during leaping (Biewener 2003), easily matching the values used here. The required speed values for takeoff we calculated could be lowered if we assumed a coefficient of lift above 1.5, similar to those seen during take off in extant birds (Usherwood 2009) or if we reduced our mass estimates. Microraptor has an 939 elongated hindlimb, especially when compared to basal birds of similar snout-vent 940 length (Dececchi and Larsson 2013). These proportionately longer hindlimbs may have

941 not only increased top running speed, as leg length is related to stride length and speed 942 (Garland and Janis 1993; Hoyt et al. 2000), but also leads to an overestimation of body 943 mass because body masses for theropods are generally derived from femur length 944 (Dececchi and Larsson 2013). If we reduce the mass of Microraptor gui (IVPP V 13352) 
945 to that of a similar sized Archaeopteryx specimen (Solnhofen) we get a mass estimate 946 of between $0.4-0.6 \mathrm{~kg}$, or between $42-67 \%$ of the value used here for IVPP $\vee 13352$.

947 This is similar to differences we see between mass estimates of femur length and 3D 948 models for LVH 0026 (Tables S1,14). Using $0.6 \mathrm{~kg}$ for Microraptor, values greater that $9491.0 \mathrm{bw}$ are achieved at speeds of only $3.8 \mathrm{~m} / \mathrm{s}$, and even less if $\mathrm{Cl}$ values closer to 950 extant birds of 1.64 are used. This suggests that at reasonable speeds, even with a 951 coefficient of lift below that of extant birds, Microraptor was likely capable of ground 952 based take off. Also during leaping take off, the horizontal velocity of birds increases 953 rapidly after the first few strokes (Berg and Biewener 2010). Therefore, effective flight 954 strokes coupled with a strong ability to jump would supply ample velocity to help 955 achieve vertical takeoff. Although no single locomotory behaviour tested here surpasses minimal 957 thresholds for high incline running or powered flight, a flight stroke in stem avians may 958 have had performance benefits to biomechanical scenarios that are more difficult to 959 test. Specifically, feathered forelimbs, coupled with a nascent flight stroke, may have 960 contributed subtle, but evolutionarily advantageous performance benefits to high speed 961 maneuvering and braking and balancing during prey capture. Even slight performance 962 enhancements to vertical and horizontal leaping may have had highly positive adaptive 963 effects. Enhancements of even a few percent may had tremendous advantages to these 964 animals, particularly if we compare the small margins of performance differences of 965 extant predator-prey interactions. Unlike leaping, WAIR is a behavior with minimal 966 thresholds that must be overcome. As such incremental gains cannot be achieved until 967 that threshold is reached, something that we find, despite our relaxed conditions, is not 
968 present in the majority of non-avian theropods and may have been restricted solely to 969 the microraptorines and avians. Thus the hypothesis that incremental gains in WAIR 970 would have adaptive benefits and drove forelimb and pectoral evolution in non-avian 971 theropods is not supported as no non-paravian maniraptoran show any capability to 972 perform this behavior.

973

974

\section{CONCLUSION}

975

All models tested here suggest that that the feathered forelimbs of all non-

976 paravian theropods and most non-avian theropods were not capable of surpassing the minimal physical thresholds of powered flight and WAIR. The origin of pennaceous feathers was not tied to a dramatic locomotory shift in these early non-avian theropods. Non-paravian taxa such as Caudipteryx, Similicaudipteryx, and Yixianosaurus have forelimb feathers greater than $100 \mathrm{~mm}$ in length, and similar sized feathers are suspected on other oviraptorosaurs (Paul 2002; Hop and Orsen 2004), large dromaeosaurs (Depalma et al. 2015) and even ornithomimids (Zelenitsky et al. 2012; van der Reest et al. 2016). These structures represent a significant energetic investment for structures that we estimate to have had minimal locomotory benefits. Moreover, the symmetry of the vanes of the pennaceous feathers in these taxa would 986 make the feathers aeroelastically unstable, further constraining their use in a locomotor context (even the pennaceous feathers of microraptorines may have been somewhat unstable during aerial locomotion, with vane asymmetries below the critical values for functional aeroelastic flutter reduction see Feo et al. 2015). These taxa also possessed large tail feathers that were likely used for display (Pittman et al. 2013; Persons et al. 
9912014 ) and feather melanin based pigmentation likely coincides with the origin of

992 pennaceous feathers ( $\mathrm{Li}$ et al. 2010, 2014). This suggests other non-locomotory

993 functions such as display or brooding were likely significant evolutionary driver for

994 pennaceous feather growth (Hopp and Orsen 2004; Zelenitsky et al. 2012).

995

996 The mosaic evolution of flight related characters suggests the evolution of the flight

997 stroke was not continuous in this clade, nor driven by a single overall driver. If different

998 behavioural traits or selective regimes and not a single locomotory function were driving

999 the evolution of feather elongation, one may not expect the concordance of "pre-flight"

1000 characters in different coelurosaur clades or even in all members of a single clade. This

1001 would explain the non-uniform distribution of traits such as the elongated forelimbs with

1002 well-developed feathers (Dececchi and Larsson 2013; Godefroit et al. 2013; Foth et al.

1003 2014), laterally facing glenoid (Gao et al. 2012), and an ossified sternum for muscle

1004 attachment (Zheng et al. 2014).

1005

1006 Although it is beyond the scope of this paper to speculate on which driver or

1007 combination of drivers led to feather elongation and forelimb musculoskeletal evolution

1008 for powered flight, we suggest that future research not focus on any single event or

1009 "pathway" to attempt to explain pre-avian evolution of characters later exapted into the

1010 flight apparatus. Given the time between the Paravian-avian split and the appearance of

1011 the Jehol microraptorines is approximately 40 million years, estimated from the oldest

1012 known paravian Anchiornis (161 Ma) and Microraptor (120 Ma) (Xu et al. 2000; Xu et al.

1013 2009) a single continuous locomotory based evolutionary driver is unlikely. Moreover, it 
1014 seems unparsimonious to argue that refining flapping based locomotion was central to

1015 the evolution of maniraptorans when the lineages show marked difference in their

1016 ecology, body size, limb usage and feather extent.

1017

1018 Although the selective pressures for each of these traits is unknown, what is apparent is

1019 it that pennaceous feathers and other critical characters related to the evolution of

1020 powered flight were not originally adapted for significantly different locomotion. It is also

1021 clear that WAIR was not a major driver for the evolution for much of Maniraptora or

1022 even Paraves. These findings reshape how we view the origins of birds and the

1023 evolution of different maniraptoran clades and refocus our investigations to look at taxa

1024 not as steps of a ladder towards the origin of flight, but as organisms adapting to the

1025 unique demands of their immediate behavioural and ecological surroundings.

1026

1027

REFERENCES

1028

1029

1030

1031

1032

1033

1034

1035

1036

1037

1038

1039

1040

1041

Aigeldinger, T., and F. Fish. 1995. Hydroplaning by ducklings: overcoming limitations to swimming at the water surface. J. Exp. Biol. 198:1567-1574.

Alexander, D. E., E. Gong, L. D. Martin, D. A. Burnham, and A. R. Falk. 2010. Model tests of gliding with different hindwing configurations in the four-winged dromaeosaurid Microraptor gui. Proc. Natl. Acad. Sci. U. S. A. 107:2972-2976.

Allen, V., K. T. Bates, Z. Li, and J. R. Hutchinson. 2013. Linking the evolution of body shape and locomotor biomechanics in bird-line archosaurs. Nature 497:104-107.

Askew, G. N., and R. L. Marsh. 2001. The mechanical power output of the pectoralis muscle of blue-breasted quail (Coturnix chinensis): the in vivo length cycle and its implications for muscle performance. J. Exp. Biol. 204:3587-3600.

Askew, G. N., R. L. Marsh, and C. P. Ellington. 2001. The mechanical power output of the flight muscles of blue-breasted quail (Coturnix chinensis) during take-off. J. Exp. Biol. 204:3601-3619. 
1042 Baier, D. B., S. M. Gatesy, and F. A. Jenkins. 2007. A critical ligamentous mechanism in 1043 the evolution of avian flight. Nature 445:307-310.

1044 Barrett, P. M., D. C. Evans, and N. E. Campione. 2015. Evolution of dinosaur epidermal 1045 structures. Biol. Lett. 11 (6): 20150229

1046 Bell, A., and L. M. Chiappe. 2011. Statistical approach for inferring ecology of Mesozoic 1047 birds. J. Syst. Palaeontol. 9:119-133.

1048 Benson, R. B. J., and J. N. Choiniere. 2013. Rates of dinosaur limb evolution provide 1049 evidence for exceptional radiation in Mesozoic birds. Proc. R. Soc. B: 280. 20131780.

1050 Berg, A. M., and A. A. Biewener. 2010. Wing and body kinematics of takeoff and landing 1051 flight in the pigeon (Columba livia). J. Exp. Biol. 213:1651-1658.

1052 Biewener, A. A. 2003. Animal Locomotion. Oxford University Press.

1053 Bock, W. J. 2013. The furcula and the evolution of avian flight. Paleontol. J. 47:123610541244.

1055 Bolwig, N. 1973. Agonistic and sexual behavior of the African Ostrich (Struthio 1056 camelus). Condor 75:100-105.

1057 Bonser, R., and J. Rayner. 1996. Measuring leg thrust forces in the common starling. J. 1058 Exp. Biol. 199:435-439.

1059 Brusatte, S. L., G. T. Lloyd, S. C. Wang, and M. A. Norell. 2014. Gradual assembly of 1060 avian body plan culminated in rapid rates of evolution across the dinosaur-bird 1061 transition. Curr. Biol. 24:2386-2392.

1062 Burch, S. H. 2014. Complete forelimb myology of the basal theropod dinosaur Tawa 1063 hallae based on a novel robust muscle reconstruction method. J. Anat. 225:271-297.

1064 Burgers, P., and L. M. Chiappe. 1999. The wing of Archaeopteryx as a primary thrust 1065 generator. Nature 399:60-62.

1066 Butler, R. J., P. M. Barrett, S. Nowbath, and P. Upchurch. 2009. Estimating the effects 1067 of sampling biases on pterosaur diversity patterns: implications for hypotheses of $1068 \mathrm{bird/pterosaur} \mathrm{competitive} \mathrm{replacement.} \mathrm{Paleobiology} \mathrm{35:432-446.}$

1069 Caple, G., R. P. Balda, and W. R. Willis. 1983. The physics of leaping animals and the 1070 evolution of preflight. Am. Nat. 121:455-476.

1071 Carey, J. R. and J. Adams. 2001. The preadaptive role of parental care in the evolution 1072 of avian flight. Archaeopteryx 19:97-108.

1073 Chatterjee, S., and R. J. Templin. 2004. 12. Feathered Coelurosaurs from China: New 1074 Light on the Arboreal Origin of Avian Flight. Feathered Dragons: Studies on the 1075 Transition from Dinosaurs to Birds 251. Indiana University Press. 
1076 Chatterjee, S., and R. J. Templin. 2007. Biplane wing planform and flight performance 1077 of the feathered dinosaur Microraptor gui. Proc. Natl. Acad. Sci. U. S. A. 104:157610781580.

1079 Christensen, G. C. 1970. The chukar partridge: Its introduction, life history, and 1080 management. Nevada Dep. Fish and Game, Reno. Biol. Bull. No. 4. 82pp.

1081 Christensen, C. 1996. Chukar: Alectoris chukar. Pp. 1-20 in A Poole, F Gill, eds. The 1082 Birds of North America (0):258. Philedelphia, PA: The Academy of Natural Sciences of 1083 Philedelphia.

1084 Christian, A., and T. Garland Jr. 1996. Scaling of limb proportions in monitor lizards 1085 (Squamata: Varanidae). J. Herpetol. 30:219-230.

1086 Christiansen, P., and R. A. Fariña. 2004. Mass prediction in theropod dinosaurs. Hist. 1087 Biol. 16:85-92.

1088 Clemente, C. J., G. G. Thompson, and P. C. Withers. 2009. Evolutionary relationships 1089 of sprint speed in Australian varanid lizards. J. Zool. 278:270-280.

1090 Codd, J. R., P. L. Manning, M. A. Norell, and S. F. Perry. 2008. Avian-like breathing 1091 mechanics in maniraptoran dinosaurs. Proc. Biol. Sci. 275:157-161.

1092 Dececchi, T. A., and H. C. E. Larsson. 2011. Assessing arboreal adaptations of bird 1093 1094 antecedents: testing the ecological setting of the origin of the avian flight stroke. PLoS One 6:e22292.

1098 Dececchi, T. A., and H. C. E. Larsson. 2009. Patristic evolutionary rates suggest a 1099 1100

Dececchi, T. A., and H. C. E. Larsson. 2013. Body and limb size dissociation at the origin of birds: uncoupling allometric constraints across a macroevolutionary transition. Evolution 67:2741-2752. punctuated pattern in forelimb evolution before and after the origin of birds.

1101 Dececchi, T. A., H. Larsson, and D. Hone. 2012. Yixianosaurus longimanus 1102 (Theropoda: Dinosauria) and its bearing on the evolution of Maniraptora and ecology of 1103

1104 Dial, K. P. 2003. Wing-assisted incline running and the evolution of flight. Science 1105 299:402-404.

1106 Dial, K. P., and B. E. Jackson. 2010. When hatchlings outperform adults: locomotor development in Australian brush turkeys (Alectura lathami, Galliformes). Proc.R. Soc. B: 1108282.

1109 Dial, K. P., B. E. Jackson, and P. Segre. 2008. A fundamental avian wing-stroke 1110 provides a new perspective on the evolution of flight. Nature 451:985-989. Nature 
1111 Publishing Group.

1112 Dial, K. P., R. J. Randall, and T. R. Dial. 2006. What use is half a wing in the ecology 1113 and evolution of birds? Bioscience 56:437-445.

1114 Dudley, R. 2002. The biomechanics of insect flight: form, function, evolution. Princeton 1115 University Press.

1116 Dudley, R., G. Byrnes, S. P. Yanoviak, B. Borrell, R. M. Brown, and J. A. McGuire. 1117 2007. Gliding and the functional origins of flight: biomechanical novelty or necessity?

1118 Annu. Rev. Ecol. Evol. Syst. 38:179-201.

1119 Dyke, G., R. de Kat, C. Palmer, J. van der Kindere, D. Naish, and B.

1120 Ganapathisubramani. 2013. Aerodynamic performance of the feathered dinosaur

1121 Microraptor and the evolution of feathered flight. Nat. Commun. 4:2489.

1122 Earls, K. D. 2000. Kinematics and mechanics of ground take-off in the starling Sturnis

1123 vulgaris and the quail Coturnix coturnix. J. Exp. Biol. 203:725-739.

1124 Elzanowski, A. 2002. Archaeopterygidae (Upper Jurassic of Germany). Mesozoic birds:

1125

1126 above the heads of dinosaurs 129-159. University of California Press Berkeley, California.

1127 Ennos, A.R., Hickson, J.R.E. and A. Roberts. 1995. Functional morphology of the vanes of the flight feathers of the pigeon Columba livia. J. Exp. Biol. 198:1219-1228.

1129

Erickson, G. M., O. W. M. Rauhut, Z. Zhou, A. H. Turner, B. D. Inouye, D. Hu, and M. A. Norell. 2009. Was dinosaurian physiology inherited by birds? Reconciling slow growth in Archaeopteryx. PLoS One 4:e7390.

1132 Evangelista, D., S. Cam, T. Huynh, A. Kwong, H. Mehrabani, K. Tse, and R. Dudley. 2014. Shifts in stability and control effectiveness during evolution of Paraves support aerial maneuvering hypotheses for flight origins. PeerJ 2:e632.

Feo, T. J., D. J. Field, and R. O. Prum. 2015. Barb geometry of asymmetrical feathers reveals a transitional morphology in the evolution of avian flight. Proc. R. Soc. B 282. 20142864 body mass estimation in modern and fossil flying birds. PLoS One 8:e82000.

1140 Foth, C., H. Tischlinger, and O. W. M. Rauhut. 2014. New specimen of Archaeopteryx provides insights into the evolution of pennaceous feathers. Nature 511:79-82.

1142 Fowler, E. 2011. "Pavo cristatus" (On-line), Animal Diversity Web. Accessed December 1143 17, 2015 at http://animaldiversity.org/accounts/Pavo_cristatus/

1144 Fowler, D. W., E. A. Freedman, J. B. Scannella, and R. E. Kambic. 2011. The predatory 1145 ecology of Deinonychus and the origin of flapping in birds. PLoS One 6:e28964. 
1146 Gao, C., E. M. Morschhauser, D. J. Varricchio, J. Liu, and B. Zhao. 2012. A second 1147 soundly sleeping dragon: new anatomical details of the Chinese troodontid Mei long 1148 with implications for phylogeny and taphonomy. PLoS One 7:e45203.

1149 Gardiner, J. D., and R. L. Nudds. 2011. No apparent ecological trend to the flightinitiating jump performance of five bat species. J. Exp. Biol. 214:2182-2188.

1151 Garland, T., and C. M. Janis. 1993. Does metatarsal/femur ratio predict maximal 1152 running speed in cursorial mammals? J. Zool. 229:133-151.

1153 Gatesy, S. M. 1999. Guineafowl hind limb function. I: Cineradiographic analysis and 1154 speed effects. J. Morphol. 240:115-125.

1155 Gatesy, S. M., and D. B. Baier. 2005. The origin of the avian flight stroke: a kinematic and kinetic perspective. Paleobiology 31:382-399.

1157 Gatesy, S. M., and A. A. Biewener. 1991. Bipedal locomotion: effects of speed, size and 1158 limb posture in birds and humans. J. Zool. 224:127-147.

1159 Glassey, B., and S. Forbes. 2002. Begging and Asymmetric Nestling Competition. Pp. $1160 \quad 269-281$ in The Evolution of Begging.

1161 Glen, C. L., and M. B. Bennett. 2007. Foraging modes of Mesozoic birds and non-avian 1162 theropods. Curr. Biol. 17:R911-2.

1163 Godefroit, P., H. Demuynck, G. Dyke, D. Hu, F. Escuillié, and P. Claeys. 2013. Reduced plumage and flight ability of a new Jurassic paravian theropod from China. Nat. Commun. 4:1394..

1166 Godefroit, P., S. M. Sinitsa, D. Dhouailly, Y. L. Bolotsky, A. V. Sizov, M. E. McNamara, M. J. Benton, and P. Spagna. 2014. A Jurassic ornithischian dinosaur from Siberia with both feathers and scales. Science 345:451-455.

1169 Gong E.P., Martin L.D., Burnham D.A., Falk A.R. and L.H. Hou.2012. A new species of Microraptor from the Jehol Biota of northeastern China Palaeoworld. 21: 81-91.

1171 Grajal, A., S. D. Strahl, R. Parra, M. Gloria Dominguez, and A. Neher. 1989. Foregut 1172 fermentation in the hoatzin, a neotropical leaf-eating bird. Science 245:1236-1238.

1173 Greenewalt, C. H. 1962. Dimensional relationships for flying animals. Smithsonian 1174 miscellaneous collections 144:1-46.

1175 Greenewalt, C. H. 1975. The Flight of Birds: The Significant Dimensions, Their 1176 Departure from the Requirements for Dimensional Similarity, and the Effect on Flight 1177 Aerodynamics of That Departure. Trans. Amer. Philo. Soc. 65:1-67.

1178 Günther, M. M., H. Ishida, H. Kumakura, and Y. Nakano. 1991. The jump as a fast 1179 1180 mode of locomotion in arboreal and terrestrial biotopes. Z. Morphol. Anthropol. 78:341372. 
1181 Hamburger, V., and R. Oppenheim. 1967. Prehatching motility and hatching behavior in 1182 the chick. J. Exp. Zool. 166:171-203.

1183 Han, G., L. M. Chiappe, S.-A. Ji, M. Habib, A. H. Turner, A. Chinsamy, X. Liu, and L. 1184 Han. 2014. A new raptorial dinosaur with exceptionally long feathering provides insights 1185 into dromaeosaurid flight performance. Nat. Commun. 5:4382.

1186 Hanna, J. B., and D. Schmitt. 2011. Locomotor energetics in primates: gait mechanics 1187 and their relationship to the energetics of vertical and horizontal locomotion. Am. J. 1188 Phys. Anthropol. 145:43-54.

1189 Harper, H. T., B. H. Harry, and W. D. Bailey. 1958. The Chukar Partridge in 1190 California. Calif. Fish and Game 44:5-50.

1191 Hartman, F. A. 1961. Locomotor mechanisms of birds. Smithsonian Miscellaneous 1192 Collections 143:1-91.

1193 Heers, A. M, B. W. Tobalske, and K. P. Dial. 2011. Ontogeny of lift and drag production 1194 in ground birds. J. Exp. Biol. 214: 717-725

1195 Heers, A. M., and K. P. Dial. 2012. From extant to extinct: locomotor ontogeny and the 1196 evolution of avian flight. Trends Ecol. Evol. 27:296-305.

1197 Heers, A. M., K. P. Dial, and B. W. Tobalske. 2014. From baby birds to feathered 1198 dinosaurs: incipient wings and the evolution of flight. Paleobiology 40:459-476.

1199 Henery, H.T., Ellerby, D.J. and R. L. Marsh. 2005. Performance of guinea fowl Numida 1200 meleagris during jumping requires storage and release of elastic energy. J. Exp. Biol. 1201 208: 3293-3302

1202 Heppner, F. H., and J. G. T. Anderson. 1985. Leg thrust important in flight take-off in the 1203 pigeon. J. Exp. Biol. 114:285-288.

1204 Hopp, T.P. and M.J. Orsen. 2004. Dinosaur Brooding Behavior and the Origin of Flight 1205 Feathers. In P.J. Currie, E.B. Koppelhus, M.A. Shugar and J.L. Wright (eds.), Feathered 1206 dragons: studies on the transition from dinosaurs to birds, pp. 234-250. Bloomington: 1207 Indiana University

1208 Hoyt, D. F., S. J. Wickler, and E. A. Cogger. 2000. Time of contact and step length: the 1209 effect of limb length, running speed, load carrying and incline. J. Exp. Biol. 203:2211210227.

1211 Huey, R. B. 1982. Phylogenetic and ontogenetic determinants of sprint performance in 1212 some diurnal Kalahari Lizards. Koedoe 25:43-48.

1213 Hwang, S.H., Norell, M.A., Ji, Q. and K. Gao. 2002. New specimens of Microraptor 1214 zhaoianus (Theropoda: Dromaeosauridae) from Northeastern China. Am. Mus. 1215 Novitates. 3381: 1-44. 
1216 Iriarte-Díaz, J. 2002. Differential scaling of locomotor performance in small and large 1217 terrestrial mammals. J. Exp. Biol. 205:2897-2908.

1218 Irschick, D. J., and B. C. Jayne. 1999. Comparative three-dimensional kinematics of the 1219 hindlimb for high-speed bipedal and quadrupedal locomotion of lizards. J. Exp. Biol. 202 1220 (Pt 9):1047-1065.

1221 Jackson, B. E. 2009. The allometry of bird flight performance. etd.lib.umt.edu.

1222 Jackson, B. E., P. Segre, and K. P. Dial. 2009. Precocial development of locomotor performance in a ground-dwelling bird (Alectoris chukar): negotiating a threedimensional terrestrial environment. Proc. Biol. Sci. 276:3457-3466. behaviour of the avian pectoralis: functional and evolutionary implications. J. Exp. Biol. 214:2354-2361.

1228

1229

1230

1231

1232

1233

1234

1235

1236

1237

1238

1239

1240

1241

1242

1243

1244

1245

1246

1247

1248

1249

1250

Jasinoski, S. C., A. P. Russell, and P. J. Currie. 2006. An integrative phylogenetic and extrapolatory approach to the reconstruction of dromaeosaur (Theropoda:

Eumaniraptora) shoulder musculature. Zool. J. Linn. Soc. 146:301-344.

Jetz, W., G. H. Thomas, J. B. Joy, K. Hartmann, and A. O. Mooers. 2012. The global diversity of birds in space and time. Nature 491:444-448.

Li, Q., J. A. Clarke, K.-Q. Gao, C.-F. Zhou, Q. Meng, D. Li, L. D’Alba, and M. D. Shawkey. 2014. Melanosome evolution indicates a key physiological shift within feathered dinosaurs. Nature 507:350-353.

Li, Q., K.-Q. Gao, J. Vinther, M. D. Shawkey, J. A. Clarke, L. D'Alba, Q. Meng, D. E. G. Briggs, and R. O. Prum. 2010. Plumage color patterns of an extinct dinosaur. Science 327:1369-1372.

Linthorne, N.S.P., M.S. Guzman, and L.A. Bridgett. 2005. Optimal take-off angle in the long jump. J. Sports. Sci. 23(7): 703-712.

Liu, D., Z. H. Zhou, and Y. G. Zhang. 2012. Mass estimate and evolutionary trend in Chinese Mesozoic fossil birds. Vertebr. Palasiat 50:39-52.

Lockwood, M. W. 2010. Basic Texas Birds: A Field Guide. University of Texas Press.

Longrich, N. R., J. Vinther, Q. Meng, Q. Li, and A. P. Russell. 2012. Primitive wing feather arrangement in Archaeopteryx lithographica and Anchiornis huxleyi. Curr. Biol. 22:2262-2267.

López-Calleja, M. V., and F. Bozinovic. 2000. Energetics and nutritional ecology of small herbivorous birds. Rev. Chil. Hist. Nat. 73:411-420.

Makovicky, P. J., and L. E. Zanno. 2011. Theropod diversity and the refinement of avian characteristics. Living dinosaurs: the evolutionary history of modern birds 9-29. 
1251 Marden, J. H. 1987. Maximum lift production during takeoff in flying animals. J. Exp. 1252 Biol. 130:235-258.

1253 Marden, J. H. 1994. From damselflies to pterosaurs: how burst and sustainable flight performance scales with size. Am. J. Physiol Regulatory Integrative Comp Physiol 266: 1077-1084.

1256

1257

1258

1259

1260

1261

1262

1263

1264

1265

1266

1267

1268

1269

1270

1271

1272

1273

1274

1275

1276

1277

1278

1279

1280

1281

1282

1283

Midford, P. E., T. J. Garland, and W. Maddison. 2010. PDAP: PDTREE package for Mesquite.

Mitchell, J. S., and P. J. Makovicky. 2014. Low ecological disparity in Early Cretaceous birds. Proceedings of the Royal Society of London B: Biological Sciences 281.

Mushi, E. Z., M. G. Binta, and N. J. Lumba. 2008. Behaviour of wild ostriches (Struthio camelus) at Mokolodi. Research Journal of Poultry Science 2:1-4.

Nachtigall, W. 1968. Elektrophysiologische und kinematische Untersuchungen über Start und Stop des Flugmotors von Fliegen. Z. vergl. Physiologie 61:1-20.

Nachtigall, W. 1978. Startsprung der Stubenfliege, Musca domestica (Diptera: Muscidae). Entomologica germanica.

Nachtigall, W., and D. M. Wilson. 1967. Neuro-muscular control of dipteran flight. J. Exp. Biol. 47:77-97.

Ngoenjun, P., N. Sitasuwan, and Others. 2009. Post-hatching growth and development of the Asian Paradise Flycatcher (Terpsiphone paradisi). Research Journal of Biological Sciences 4:1244-1249.

Norberg, U.M.L. 2002. Structure, form, and function of flight in engineering and the living world. J. Morphol. 252: 52-81.

Nudds, R. L., and G. J. Dyke. 2009. Forelimb posture in dinosaurs and the evolution of the avian flapping flight-stroke. Evolution 63:994-1002.

Nudds, R. L., G. J. Dyke, and J. M. V. Rayner. 2007. Avian brachial index and wing kinematics: putting movement back into bones. J. Zool. 272:218-226..

O'Connor, J., and Z. Zhou. 2015. Early evolution of the biological bird: perspectives from new fossil discoveries in China. J. Ornithol. 1-10.

Parsons, W. L., and K. M. Parsons. 2015. Morphological variations within the ontogeny of Deinonychus antirrhopus (Theropoda, Dromaeosauridae). PLoS One 10:e0121476..

Paul, G.S. (2002). Dinosaurs of the Air: The Evolution and Loss of Flight in Dinosaurs and Birds. Baltimore: Johns Hopkins University Press

Pennycuick, C. J. 2008. Modelling the flying bird. Elsevier. 
1284 Persons, W. S. I. V., P. J. Currie, and M. A. Norell. 2014. Oviraptorosaur tail forms and 1285 functions. Acta Palaeontol. Pol. 59:553-567.

1286 Pittman, M., S. M. Gatesy, P. Upchurch, A. Goswami, and J. R. Hutchinson. 2013. Shake a tail feather: the evolution of the theropod tail into a stiff aerodynamic surface. PLoS One 8:e63115.

1289

1290

1291

1292

1293

1294

1295

1296

1297

1298

1299

1300

1301

1302

1303

1304

1305

1306

1307

1308

1309

1310

1311

1312

1313

1314

1315

1316

1317

1318

Provine, R. R. 1981a. Development of wing-flapping and flight in normal and flapdeprived domestic chicks. Dev. Psychobiol. 14:279-291.

Provine, R. R. 1982. Preflight development of bilateral wing coordination in the chick (Gallus domesticus): effects of induced bilateral wing asymmetry. Dev. Psychobiol. 15:245-255.

Provine, R. R. 1981b. Wing-flapping develops in chickens made flightless by feather mutations. Dev. Psychobiol. 14:481-486.

Provine, R. R. 1979. "Wing-flapping" develops in wingless chicks. Behav. Neural Biol. 27:233-237.

Provini, P., B. W. Tobalske, K. E. Crandell, and A. Abourachid. 2012. Transition from leg to wing forces during take-off in birds. J. Exp. Biol. 215:4115-4124.

Prozesky OPM (1970) A field guide to the birds of southern Africa. Collins, London

Qiang, J., P. J. Currie, M. A. Norell, and J. Shu-An. 1998. Two feathered dinosaurs from northeastern China. Nature 393:753-761.

Robertson, A. M. B., and A. A. Biewener. 2012. Muscle function during takeoff and landing flight in the pigeon (Columba livia). J. Exp. Biol. 215:4104-4114.

Rydén, O., and H. Bengtsson. 1980. Differential begging and locomotory behaviour by early and late hatched nestlings affecting the distribution of food in asynchronously hatched broods of altricial birds. Zeitschrift für Tierpsychologie 53:209-224.

Savile, D. B. O. 1957. The primaries of Archaeopteryx. Auk 74:99-101..

Schaller, N. U. 2008. Structural attributes contributing to locomotor performance in the ostrich. archiv.ub.uni-heidelberg.de.

Schouest, L. P., Jr, M. Anderson, and T. A. Miller. 1986. The ultrastructure and physiology of the tergotrochanteral depressor muscle of the housefly, Musca domestica. J. Exp. Zool. 239:147-158.

Schutt, W. A., Jr, J. S. Altenbach, Y. H. Chang, D. M. Cullinane, J. W. Hermanson, F. Muradali, and J. E. Bertram. 1997. The dynamics of flight-initiating jumps in the common vampire bat Desmodus rotundus. J. Exp. Biol. 200:3003-3012.

Sears, K. E., R. R. Behringer, J. J. Rasweiler, and L. A. Niswander. 2006. Development of bat flight: Morphologic and molecular evolution of bat wing digits. Proceedings of the 
1319 National Academy of Sciences 103:6581-6586.

1320 Sellers, W. I., and P. L. Manning. 2007. Estimating dinosaur maximum running speeds using evolutionary robotics. Proc. Biol. Sci. 274:2711-2716.

1322 Senter, P. 2006a. Comparison of forelimb function between Deinonychus and 1323 Bambiraptor (Theropoda: Dromaeosauridae). J. Vert. Paleontol. 26:897-906.

1324 Senter, P. 2006b. Scapular orientation in theropods and basal birds, and the origin of 1325 flapping flight. Acta Palaeontol. Pol. 51:305-313.

Silveira, L. F., Höfling, E., Moro, M. E. G., Antonio do Nascimento, A. and Arantes, I. G. (2001) Order Tinamiformes (Tinamous), in Biology, Medicine, and Surgery of South American Wild Animals (ed M. E. Fowler), lowa State University Press, Ames, lowa, USA.

Taylor, C. R., S. L. Caldwell, and V. J. Rowntree. 1972. Running up and down hills: some consequences of size. Science 178:1096-1097.

Tobalske, B. W., D. L. Altshuler, and D. R. Powers. 2004. Take-off mechanics in hummingbirds (Trochilidae). J. Exp. Biol. 207:1345-1352.

1334

1335

1336

1337

1338

1339

1340

1341

1342

1343

1344

1345

1346

1347

1348

1349

1350

1351

1352 1353

Tobalske, B. W., and K. P. Dial. 2007. Aerodynamics of wing-assisted incline running in birds. J. Exp. Biol. 210:1742-1751.

Tobalske, B. W., and K. P. Dial. 2000. Effects of body size on take-off flight performance in the Phasianidae (Aves). J. Exp. Biol. 203:3319-3332.

Tobalske, B. W., T. L. Hedrick, K. P. Dial, and A. A. Biewener. 2003. Comparative power curves in bird flight. Nature 421:363-366.

Toro, E., A. Herrel, and D. Irschick. 2004. The evolution of jumping performance in the Caribbean Anolis lizards: Solutions to biomechanical trade-offs. Am. Nat. 163 (6):844856.

Trimarchi, J. R., and A. M. Schneiderman. 1995. Initiation of flight in the unrestrained fly, Drosophila melanogaster. J. Zool. 235:211-222.

Turner, A. H., P. J. Makovicky, and M. A. Norell. 2012. A review of dromaeosaurid systematics and paravian phylogeny. Bull. Am. Mus. Nat. Hist. 371: 1-206.

Usherwood, J. R. 2009. The aerodynamic forces and pressure distribution of a revolving pigeon wing. Exp. Fluids 46:991-1003.

van der Reest, A. J., A. P. Wolfe, and P. J. Currie. 2016. A densely feathered ornithomimid (Dinosauria: Theropoda) from the Upper Cretaceous Dinosaur Park Formation, Alberta, Canada. Cretaceous Research 58: 108-117.

Wakai, M. and N.P. Linthorne. 2005. Optimum take-off angle in the standing long jump. Human Move. Sci. 24(1): 81-96. 
1354 Wang, M.; Zheng, X.; o'Connor, J. K.; Lloyd, G. T.; Wang, X.; Wang, Y.; Zhang, X.; 1355 Zhou, Z. (2015). "The oldest record of ornithuromorpha from the early cretaceous of 1356 China". Nature Communications 6: 6987

1357

1358

1359

1360

1361

1362

1363

1364

1365

1366

1367

1368

1369

1370

1371

1372

1373

1374

1375

1376

1377

1378

1379

1380

1381

1382

1383

1384

1385

1386

1387

Witton, M. P., and M. B. Habib. 2010. On the size and flight diversity of giant pterosaurs, the use of birds as pterosaur analogues and comments on pterosaur flightlessness. PLoS One 5:e13982.

Wunder, B. A., and P. R. Morrison. 1974. Red squirrel metabolism during incline running. Comp. Biochem. Physiol. A Comp. Physiol. 48:153-161.

Xu, X., Wang, X. and X. Wu. 1999. A dromaeosaurid dinosaur with a filamentous integument from the Yixian Formation of China. Nature 401: 262-266

Xu, X., Z. Zhou, and X. Wang. 2000. The smallest known non-avian theropod dinosaur. Nature, 408: 705-708.

Xu, X. Q. Zhao, M. Norell, C. Sullivan, D. Hone, G. Erickson, X. Wang, F. Han, and Y. Guo. 2009. A new feathered maniraptoran dinosaur fossil that fills a morphological gap in avian origin. Chinese Science Bulletin 54 (3): 430-435.

Xu, X., Q. Ma, and D. Hu. 2010a. Pre-Archaeopteryx coelurosaurian dinosaurs and their implications for understanding avian origins. Chin. Sci. Bull. 55:3971-3977..

Xu, X., X. Zheng, C. Sullivan, X. Wang, L. Xing, Y. Wang, X. Zhang, J. K. O'Connor, F. Zhang, and Y. Pan. 2015. A bizarre Jurassic maniraptoran theropod with preserved evidence of membranous wings. Nature 521:70-73.

$\mathrm{Xu}, \mathrm{X}$., X. Zheng, and H. You. 2010b. Exceptional dinosaur fossils show ontogenetic development of early feathers. Nature 464:1338-1341.

Xu, X., Z. Zhou, R. Dudley, S. Mackem, C.-M. Chuong, G. M. Erickson, and D. J. Varricchio. 2014. An integrative approach to understanding bird origins. Science 346:1253293.

Xu, X., Z. Zhou, X. Wang, X. Kuang, F. Zhang, and X. Du. 2003. Four-winged dinosaurs from China. Nature 421:335-340.

Yalden, D. W. 1971. The flying ability of Archaeopteryx. Ibis 113:349-356.

Yalden, D. W. 1984. What size was Archaeopteryx? Zool. J. Linn. Soc. 82:177-188.

Zelenitsky, D. K., F. Therrien, G. M. Erickson, C. L. DeBuhr, Y. Kobayashi, D. A. Eberth, and F. Hadfield. 2012. Feathered non-avian dinosaurs from North America provide insight into wing origins. Science 338:510-514.

Zheng, X., J. O'Connor, X. Wang, M. Wang, X. Zhang, and Z. Zhou. 2014. On the 
1388

1389

1390

1391

1392

1393

1394

1395

1396

1397

1398

1399

1400

1401

1402

1403

1404

1405

1406

1407

1408

1409

1410

1411

1412

1413

1414

1415

1416

1417

1418

1419

1420

1421

1422

1423

1424

1425

1426

1427

1428

absence of sternal elements in Anchiornis (Paraves) and Sapeornis (Aves) and the complex early evolution of the avian sternum. Proc. Natl. Acad. Sci. U. S. A. 111:13900-13905.

Zhou, Z., and F. Zhang. 2003a. Anatomy of the primitive bird Sapeornis chaoyangensis from the Early Cretaceous of Liaoning, China. Can. J. Earth Sci. 40:731-747.

Zhou, Z., and F. Zhang. 2003b. Jeholornis compared to Archaeopteryx, with a new understanding of the earliest avian evolution. Naturwissenschaften 90:220-225.

Figure 1.

Wing loading values in non-avian theropods, each open circle denotes the value per specimen for taxa with multiple specimens included in analysis. Note that only a minority of paravian specimens are below the lines denoting values pre WAIR quadruped crawling in Chukar (3dph) and when fledging occurs (10 dph) as well as WAIR capable Brush Turkeys.

Figure 2.

Evolution of WAIR performance. Estimated evolutionary ranges of WAIR stages I and II (Dial 2003, Heers et al. 2012, 2014) are mapped over a phylogeny of selected Coelurosaurians. Upper lines are for $90^{\circ}$ flap angles and lower lines for $50^{\circ}$ flap angles. Flight-stroke specific characters are mapped onto the phylogeny: 1, forelimb integument; 2, pennaceous feathers on forelimb; 3, L-shaped scapulocoracoid; 4 , laterally facing glenoid; 5 , asymmetrical remigies; 6 , alula; 7 , incipient ligament-based shoulder stabilization; 8, dorsolaterally facing glenoid; 9 , full ligament-based shoulder stabilization. Silhouettes from phylopic images by B. McFeteers, T.M. Keesey, M. Martynuick, and original.

Figure 3.

Evolution of flight stroke enhancements to flap running (orange) and vertical leaping (blue) performance. Estimated ranges are mapped over a phylogeny of selected Coelurosaurians. Averages are presented when multiple specimens are available. Upper lines are for $90^{\circ}$ flap angles and lower lines for $50^{\circ}$ flap angles. Flight-stroke 
1429 specific characters are mapped onto the phylogeny: 1 , forelimb integument; 2 , pennaceous feathers on forelimb; L-shaped scapulocoracoid; 4, laterally facing glenoid; 5, asymmetrical remigies; 6 , alula; 7 , incipient ligament-based shoulder stabilization; 8 , dorsolaterally facing glenoid; 9 , full ligament-based shoulder stabilization. Silhouettes from phylopic images by B. McFeteers, T.M. Keesey, M. Martynuick, and original.

Figure 4.

3D scatterplot of values for Chukars modeled for the first 70 days of growth. 2D projections of the values are shown on each axis-pair plane with grey circles. Age, pectoral limb muscle mass, wing loading, and WAIR performance data are from Heers and Dial. (2015). Maximum WAIR angle was limited to 100 degrees. Regressions were neither linear nor unimodal suggesting a complex interaction between musculoskeleletal and aerofoil ontogeny and performance. Mass $(\mathrm{g})$ was estimated from age by the quadratic equation $5.730818+3.472647^{*} x+-0.011605{ }^{*} x^{2}+0.000661^{*} x^{3}\left(R^{2}=0.9902\right)$; only ages less than 100 days were used. Percent pectoral mass was estimated from mass by the quadratic equation $0.858022+0.231592^{*} x-0.000658^{*} x^{2}+5.9340^{-7 *} x^{3}\left(R^{2}\right.$ $=0.92$ ). Wing loading was estimated from mass by the quadratic equation $1.692164+-$ $0.018717^{*} x+8.756264^{-5 *} x^{2}+-9.483335^{-8 *} x^{3}\left(R^{2}=0.69\right)$. Maximum WAIR angle was estimated from mass by the quadratic equation $38.119489+1.137820^{*} x+-0.007969^{*} x^{2}$ $+1.925223 e-05^{*} x^{3}\left(R^{2}=0.9575\right)$.

Figure 5.

Regression of measured wing loading versus maximum WAIR angle in Chukar chicks aged 3-15 day post hatching and estimates for selected non-avian theropods. Chukar data are from Heers and Dial (2015). Large circles denote Chukar values with their age given as the number inside. Regression for Chukar data is $100.17-20.824 x, R 2=0.848$. Small circles denote estimated paravian theropods. Only specimens with wing loading values comparable to those seen in Chukars $\left(<2.0 \mathrm{~g} / \mathrm{cm}^{2,}=196 \mathrm{~N} / \mathrm{m}^{2}\right)$ were included. Demarcations based on Jackson et al. (2009). Non-avian theropods are: f1, Anchiornis huxleyi BMNHCPH828; f2, Anchiornis huxleyi LPM B00169; f3, Aurornis xui YFGPT5198; f4, Changyuanraptor yangi HG B016; f5, Eosinopteryx brevipenna YFGP-T5197; f6, Microraptor gui BMNHC PH 881; f7, M. gui IVPP V 13352; f8, M. hanqingi LVH 0026 (light mass estimate); f9, M. hanqingi LVH 0026 (heavy mass estimate). 


\section{Figure 1 (on next page)}

Wing loading values in non-avian theropods

Wing loading values in non-avian theropods, each open circle denotes the value per specimen for taxa with multiple specimens included in analysis. Note that only a minority of paravian specimens are below the lines denoting values pre WAIR quadruped crawling in Chukar (3dph) and when fledging occurs (10 dph) as well as WAIR capable Brush Turkeys. 


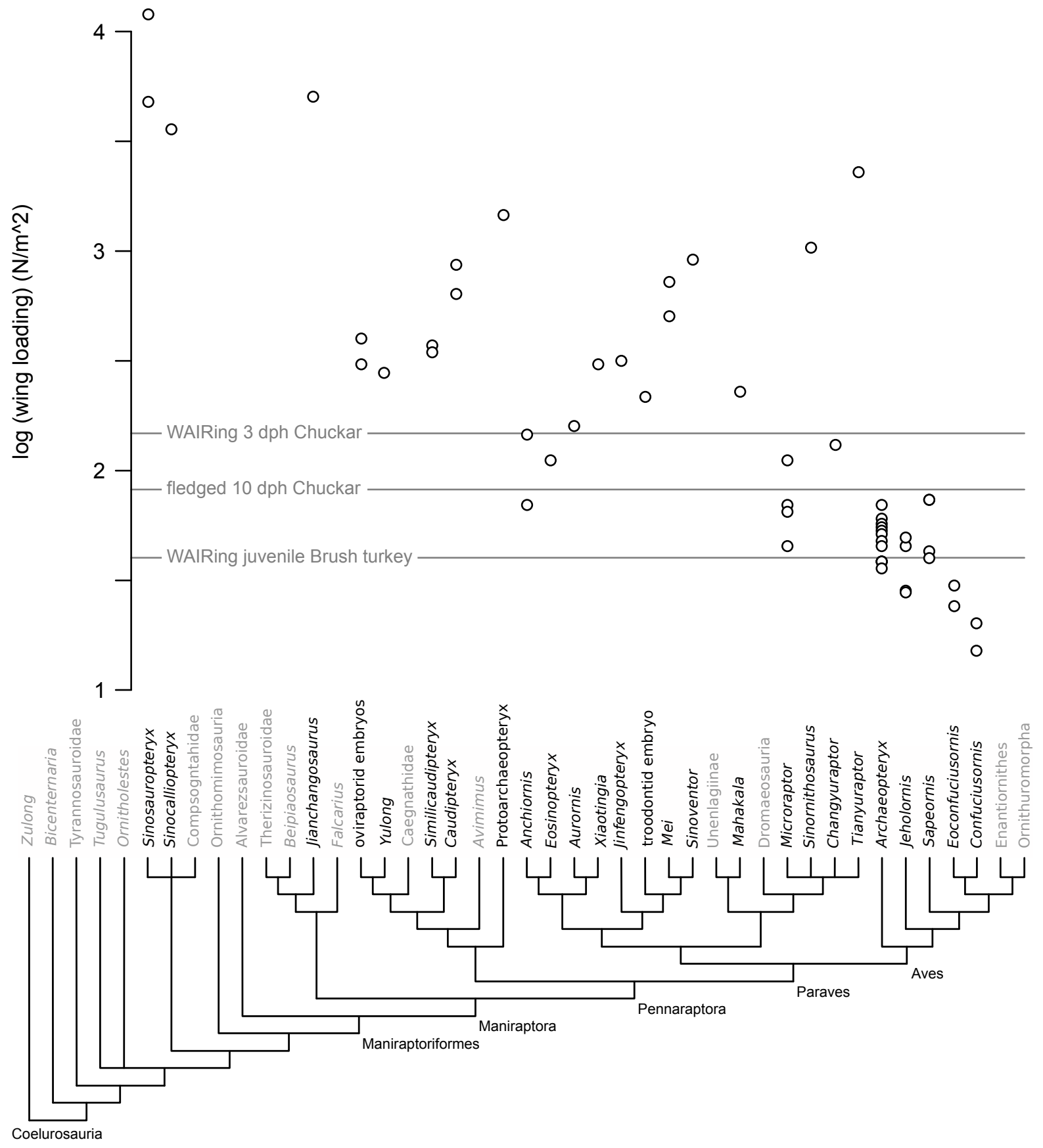




\section{Table $\mathbf{1}$ (on next page)}

Table 1

Fossil taxa examined in this study. Taxa in bold were specimens without preserved forelimb remegies for whom feather lengths were estimated based on closely related taxa or other members of the same genus. For these taxa @ based on other Archaeopteryx specimens, \# denotes estimates based on Microraptor gui, * based on Anchiornis, \$ based on Caudipteryx. For Jianchangosaurus we based our estimate on the longest preserved body feather traces, this is defensible as this clade is not know to have pennaceous remegies (Foth et al. 2014) and in other maniraptorans without remegies the integument on the distal cervicals are similar in size, if not longer, than those on the forelimbs (Currie and Chen 2001).CF indicates mass estimated based on Christiansen and Farina 2004, Liu indicates avian mass estimates based on Liu et al. 2014, Fe for avian mass estimates based on Field et al. 2013 See text for discussion of body mass calculations and wing beat frequencies. 
2

\begin{tabular}{|c|c|c|c|c|c|c|c|c|}
\hline Taxa & Reference & $\begin{array}{l}\text { wing } \\
\text { length } \\
\text { (m) }\end{array}$ & $\begin{array}{l}\text { span } \\
\text { (m) }\end{array}$ & $\begin{array}{l}\text { mass } \\
(\mathrm{kg}) \mathrm{CF}\end{array}$ & $\begin{array}{l}\text { mass } \\
(\mathrm{kg}) \text { Liu }\end{array}$ & $\begin{array}{l}\text { mass } \\
(\mathrm{kg}) \mathrm{FE}\end{array}$ & $\begin{array}{l}\text { Wing } \\
\text { Area } \\
\left(m^{\wedge} 2\right)\end{array}$ & $\begin{array}{l}\text { Wing } \\
\text { loading } \\
\text { N/M2 }\end{array}$ \\
\hline Anchiornis & Li et al. 2010 & 0.16 & 0.33 & 0.09 & - & - & 0.01 & 70 \\
\hline Anchiornis & Sullivan et al. 2010 & 0.24 & 0.50 & 0.38 & - & - & 0.03 & 146 \\
\hline Archaeopteryx & Foth et al. 2014 & 0.31 & 0.65 & - & 0.24 & - & 0.06 & 38 \\
\hline Archaeopteryx & Foth et al. 2014 & 0.31 & 0.65 & - & - & 0.36 & 0.06 & 57 \\
\hline Archaeopteryx & Mayr et al. 2007 & 0.29 & 0.61 & - & 0.23 & - & 0.06 & 38 \\
\hline Archaeopteryx & Mayr et al. 2007 & 0.29 & 0.61 & - & - & 0.32 & 0.06 & 55 \\
\hline Archaeopteryx & Elzanowski 2002 & 0.33 & 0.69 & - & 0.31 & - & 0.07 & 45 \\
\hline Archaeopteryx & Elzanowski 2002 & 0.33 & 0.69 & - & - & 0.48 & 0.07 & 70 \\
\hline Archaeopteryx & $\begin{array}{l}\text { Mayr et al. 2007, Nudds } \\
\text { and Dyke } 2010\end{array}$ & 0.26 & 0.55 & - & 0.18 & - & 0.05 & 38 \\
\hline Archaeopteryx & $\begin{array}{l}\text { Mayr et al. 2007, Nudds } \\
\text { and Dyke } 2010\end{array}$ & 0.26 & 0.55 & - & - & 0.25 & 0.05 & 53 \\
\hline Archaeopteryx & Mayr et al. 2007 & 0.27 & 0.57 & - & 0.19 & - & 0.05 & 36 \\
\hline Archaeopteryx & Mayr et al. 2007 & 0.27 & 0.57 & - & - & 0.27 & 0.05 & 51 \\
\hline Archaeopteryx & Mayr et al. 2007 & 0.19 & 0.39 & - & 0.11 & - & 0.02 & 47 \\
\hline Archaeopteryx & Mayr et al. 2007 & 0.19 & 0.39 & - & - & 0.14 & 0.02 & 60 \\
\hline Aurornis* & Godefroit et al. 2013 & 0.22 & 0.47 & 0.38 & - & - & 0.02 & 160 \\
\hline Caudipteryx & Zhou and Wang 2000 & 0.35 & 0.72 & 5.52 & - & - & 0.09 & 631 \\
\hline Caudipteryx & Sullivan et al. 2010 & 0.28 & 0.58 & 3.77 & - & - & 0.04 & 863 \\
\hline Changyuraptor \# & Han et al. 2014 & 0.68 & 1.42 & 5.64 & - & - & 0.43 & 130 \\
\hline Citipati MPC-D100/971 & Lu et al. 2013 & 0.11 & 0.22 & 0.05 & & & 0.00 & 397 \\
\hline Confuciusornis & Chiappe et al. 1999 & 0.32 & 0.67 & - & 0.14 & - & 0.09 & 15 \\
\hline Confuciusornis & Chiappe et al. 1999 & 0.32 & 0.67 & - & - & 0.19 & 0.09 & 20 \\
\hline Eoconfuciusornis & Sullivan et al. 2010 & 0.22 & 0.46 & - & 0.09 & - & 0.04 & 24 \\
\hline Eoconfuciusornis & Sullivan et al. 2010 & 0.22 & 0.46 & - & - & 0.12 & 0.04 & 30 \\
\hline Eosinopteryx & Godefroit et al. 2013 & 0.16 & 0.33 & 0.14 & - & - & 0.01 & 111 \\
\hline Jeholornis & Ji et al. 2003 & 0.41 & 0.86 & - & 0.34 & - & 0.12 & 29 \\
\hline Jeholornis & Ji et al. 2003 & 0.41 & 0.86 & - & - & 0.54 & 0.12 & 45 \\
\hline Jeholornis* & Zhou and Zhang 2002 & 0.55 & 1.15 & - & 0.60 & - & 0.21 & 28 \\
\hline Jeholornis* & Zhou and Zhang 2002 & 0.55 & 1.15 & - & - & 1.05 & 0.21 & 49 \\
\hline Jianchangosaurus & Pu et al. 2013 & 0.40 & 0.83 & 14.70 & - & - & 0.03 & 5018 \\
\hline Jinfengopteryx* & Ji et al. 2005 & 0.17 & 0.37 & 0.46 & - & - & 0.01 & 317 \\
\hline Mahakala\# & Turner et al. 2011 & 0.20 & 0.42 & 0.67 & - & - & 0.03 & 229 \\
\hline Mei long* & Gao et al. 2012 & 0.12 & 0.26 & 0.36 & - & - & 0.01 & 505 \\
\hline Mei long* & Xu and Norell 2004 & 0.15 & 0.31 & 0.73 & - & - & 0.01 & 714 \\
\hline Microraptor & Li et al. 2012 & 0.24 & 0.50 & 0.17 & - & - & 0.04 & 46 \\
\hline Microraptor & $\begin{array}{l}\text { Xu et al. 2003, Sullivan et } \\
\text { al. } 2010\end{array}$ & 0.41 & 0.86 & 0.88 & - & - & 0.12 & 69 \\
\hline Microraptor hanqingi\# & Gong et al. 2012 & 0.47 & 0.98 & 2.05 & - & - & 0.18 & 110 \\
\hline Oviraptor incertae & Lu et al. 2013 & 0.09 & 0.19 & 0.03 & & & 0.00 & 305 \\
\hline
\end{tabular}




\begin{tabular}{|c|c|c|c|c|c|c|c|c|}
\hline sedis MPC-D100/1018 & & & & & & & & \\
\hline Protarchaeopteryx & Ji and Ji 1997 & 0.26 & 0.54 & 2.58 & - & - & 0.02 & 1445 \\
\hline Sapeornis & Pu et al. 2013 & 0.44 & 0.92 & - & 0.51 & - & 0.12 & 43 \\
\hline Sapeornis & Pu et al. 2013 & 0.44 & 0.92 & - & - & 0.88 & 0.12 & 74 \\
\hline Sapeornis* & Zhou and Zhang 2003 & 0.57 & 1.21 & - & 0.80 & - & 0.20 & 40 \\
\hline Sapeornis* & Zhou and Zhang 2003 & 0.57 & 1.21 & - & - & 1.49 & 0.20 & 74 \\
\hline Similicaudipteryx & $\begin{array}{l}\text { Xu et al. 2009, Dececchi } \\
\text { and Larsson } 2013\end{array}$ & 0.40 & 0.84 & 4.23 & - & - & 0.12 & 345 \\
\hline Similicaudipteryx & $\begin{array}{l}\text { Xu et al. 2009, Dececchi } \\
\text { and Larsson } 2013\end{array}$ & 0.07 & 0.15 & 0.06 & - & - & 0.00 & 372 \\
\hline Sinocalliopteryx & Sullivan et al. 2010 & 0.37 & 0.77 & 18.43 & - & - & 0.05 & 3596 \\
\hline Sinornithoides & Russell and Dong 1993 & & & & & & & \\
\hline Sinornithosaurus & Ji et al. 2001 & 0.26 & 0.54 & 1.94 & - & - & 0.02 & 1032 \\
\hline Sinornithosaurus & Sullivan et al. 2010 & 0.19 & 0.41 & 0.29 & - & - & 0.01 & 229 \\
\hline Sinosauropteryx & Currie and Chen 2001 & 0.10 & 0.20 & 0.88 & - & - & 0.00 & 4755 \\
\hline Sinosauropteryx & Currie and Chen 2001 & 0.05 & 0.09 & 0.19 & - & - & 0.00 & 11910 \\
\hline Sinovenator* & $\begin{array}{l}\text { Benson and Choiniere } \\
2012\end{array}$ & 0.24 & 0.50 & 2.44 & - & - & 0.03 & 919 \\
\hline Tianyuraptor & $\begin{array}{l}\text { Chan et al. 2013, } \\
\text { Dececchi and Larsson } \\
2013\end{array}$ & 0.39 & 0.82 & 13.36 & - & - & 0.06 & 2272 \\
\hline $\begin{array}{l}\text { Troodon Embryo MOR } \\
246-1\end{array}$ & Varricchio et al. 2002 & 0.08 & 0.16 & 0.05 & & & 0.00 & 214 \\
\hline Xiaotingia* & Xu et al. 2011 & 0.24 & 0.50 & 0.82 & - & - & 0.03 & 305 \\
\hline Yixianosaurus & Dececchi et al. 2012 & 0.29 & 0.61 & 1.30 & - & - & 0.04 & 323 \\
\hline Yixianosaurus & Dececchi et al. 2012 & 0.29 & 0.61 & 1.89 & - & - & 0.04 & 470 \\
\hline Yulong\% & Lu et al. 2013 & 0.18 & 0.38 & 0.50 & - & - & 0.02 & 280 \\
\hline Zhenyuanlong & Lu and Brussatte. 2015 & 0.58 & 1.22 & 11.99 & - & - & 0.23 & 515 \\
\hline
\end{tabular}




\section{Figure 2 (on next page)}

Evolution of WAIR performance

Evolution of WAIR performance. Estimated evolutionary ranges of WAIR stages I and II (Dial 2003, Heers et al. 2012, 2014) are mapped over a phylogeny of selected Maniraptoriformes. Upper lines are for $90^{\circ}$ flap angles and lower lines for $50^{\circ}$ flap angles. Flight-stroke specific characters are mapped onto the phylogeny: 1, forelimb integument; 2 , pennaceous feathers on forelimb; L-shaped scapulocoracoid; 4, laterally facing glenoid; 5, asymmetrical remigies; 6. alula; 7, incipient ligament-based shoulder stabilization; 8, dorsolaterally facing glenoid; 9 , full ligament-based shoulder stabilization. The bottom coloured lines denote $50^{\circ}$ flap angles and upper coloured lines $90^{\circ}$. Silhouettes from phylopic images by B. McFeteers, T.M. Keesey, M. Martynuick, and original. 


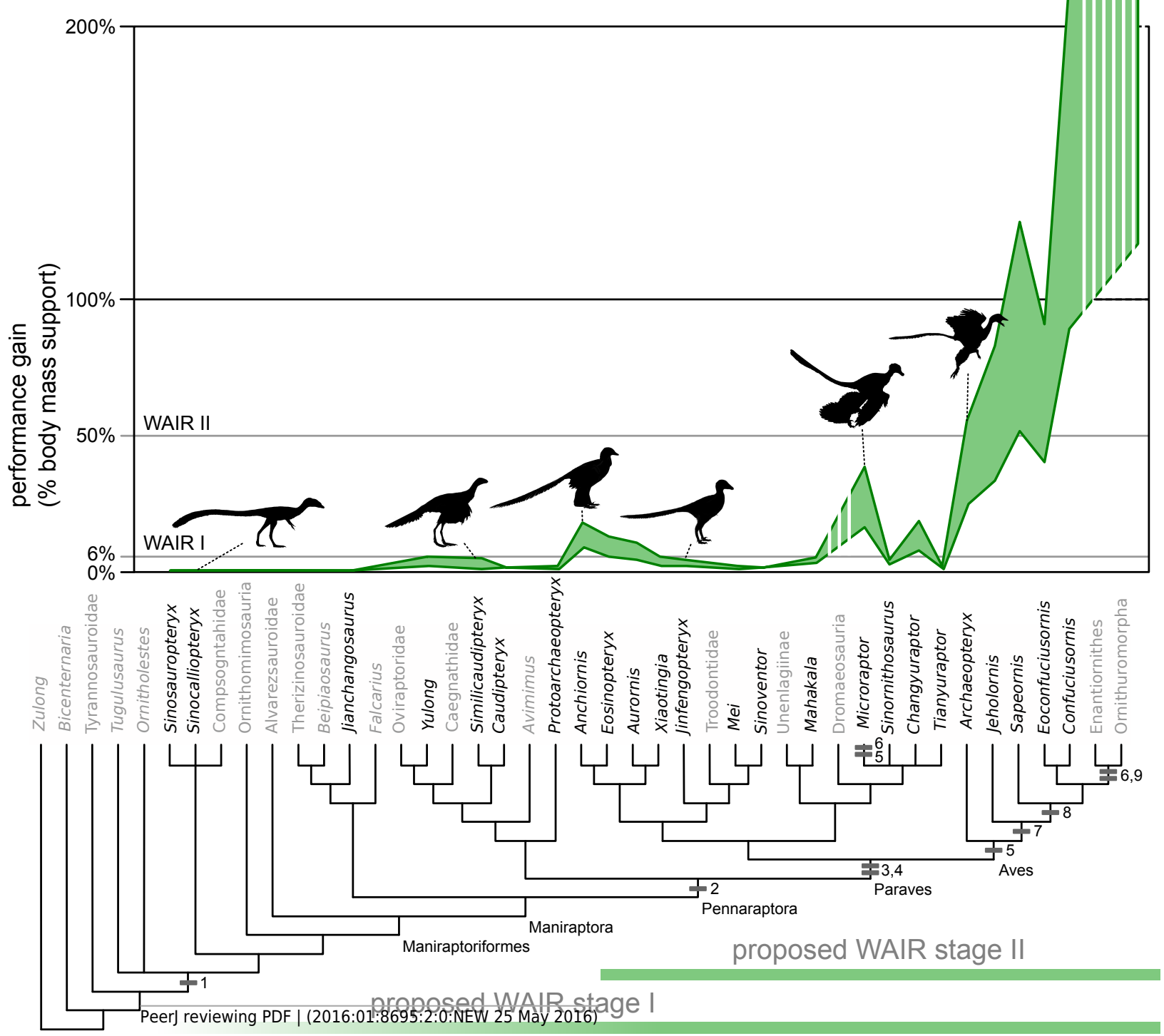




\section{Figure 3 (on next page)}

Evolution of flight stroke enhancements to flap running (orange) and vertical leaping (blue) performance.

Evolution of flight stroke enhancements to flap running (orange) and vertical leaping (blue) performance. Estimated ranges are mapped over a phylogeny of selected Maniraptoriformes. Averages are presented when multiple specimens are available. Upper lines are for $90^{\circ}$ flap angles and lower lines for $50^{\circ}$ flap angles. Flight-stroke specific characters are mapped onto the phylogeny: 1, forelimb integument; 2, pennaceous feathers on forelimb; L-shaped scapulocoracoid; 4, laterally facing glenoid; 5 , asymmetrical remigies; 6 , alula; 7 , incipient ligament-based shoulder stabilization; 8, dorsolaterally facing glenoid; 9, full ligament-based shoulder stabilization. The bottom coloured lines denote $50^{\circ}$ flap angles and upper coloured lines $90^{\circ}$. Silhouettes from phylopic images by B. McFeteers, T.M. Keesey, M. Martynuick, and original. 


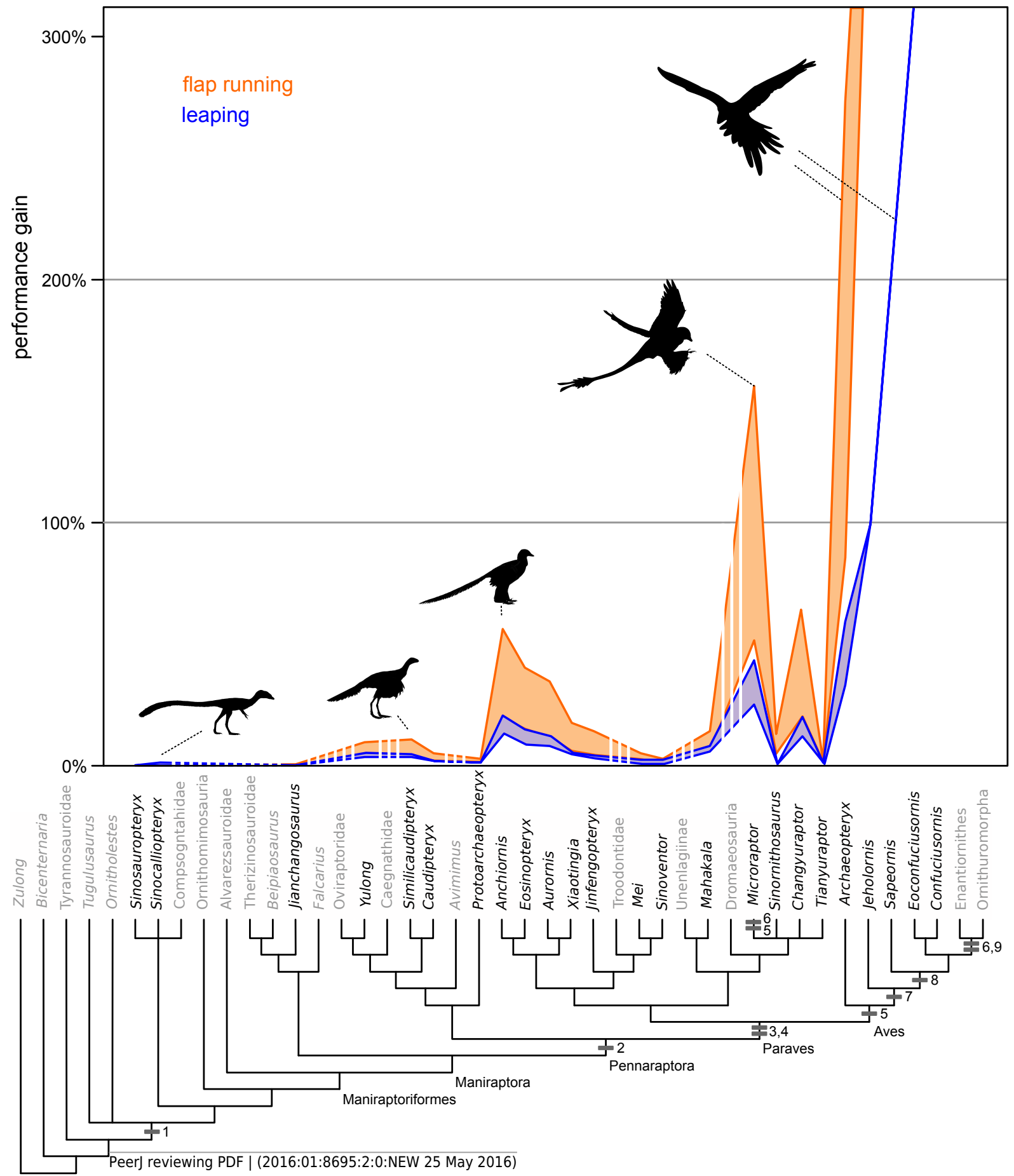




\section{Table 2 (on next page)}

Table 2

Results of equations for calculating forces produced during WAIR and takeoff. using data from extant avians. For Chukars body mass, wing area and body velocity are based on Tobalske and Dial 2007, Flapping frequency and angle are based on Jackson et al. 2009. Coefficient of lift values (Cl) based on Heers et al. 2011. For pigeons WAIR all data based on Jackson et al. 2011 except for wing area, which is taken from pigeons Crandall and Toblaske (2011) from pigeons with similar mass and wing length. For avian takeoff values are based on Tobalske and Dial 2000 and Askew et al. 2001. 


\begin{tabular}{|c|c|c|c|c|c|c|c|c|c|c|}
\hline \multirow[t]{2}{*}{ Taxon } & \multirow[t]{2}{*}{ Stage } & \multirow{2}{*}{$\begin{array}{c}\text { Body } \\
\text { Mass } \\
(\mathbf{k g})\end{array}$} & \multirow{2}{*}{$\begin{array}{l}\text { Wing } \\
\text { Area } \\
\left(m^{\wedge} 2\right)\end{array}$} & \multirow{2}{*}{$\begin{array}{c}\text { Flap } \\
\text { angle } \\
\text { (rad) }\end{array}$} & \multirow{2}{*}{$\begin{array}{l}\text { Wing } \\
\text { beat } \\
\text { (hz) }\end{array}$} & \multirow{2}{*}{$\begin{array}{l}\text { Velocity } \\
\text { (m/s) }\end{array}$} & \multirow{2}{*}{$\begin{array}{c}\text { BW } \\
\mathrm{Cl}=1.0\end{array}$} & \multirow{2}{*}{$\begin{array}{c}\text { BW } \\
\mathrm{Cl}=1.2\end{array}$} & \multirow{2}{*}{$\begin{array}{c}\text { BW } \\
\mathrm{Cl}=1.5\end{array}$} & \multirow{2}{*}{$\begin{array}{c}\text { BW } \\
\mathrm{Cl}=1.6\end{array}$} \\
\hline & & & & & & & & & & \\
\hline Chukar & 1 & 0.024 & 0.0036 & 1.57 & 22 & 0.60 & 0.06 & 0.08 & - & - \\
\hline Chukar & II & 0.222 & 0.0297 & 2.5 & 18.7 & 1.20 & 0.85 & 1.02 & - & - \\
\hline Chukar & III & 0.605 & 0.0499 & 2.16 & 18.7 & 1.50 & 0.65 & 0.78 & 0.97 & 1.02 \\
\hline Pigeon & $\begin{array}{c}\text { WAIR } \\
65^{\circ} \\
\end{array}$ & $0.42-0.47$ & 0.067 & 1.57 & $6.2-6.7$ & 1.50 & $\begin{array}{l}0.21- \\
0.26\end{array}$ & $0.25-0.31$ & $0.31-0.39$ & $0.33-0.41$ \\
\hline Pigeon & $\begin{array}{c}\text { WAIR } \\
85^{\circ} \\
\end{array}$ & $0.42-0.47$ & 0.067 & 1.57 & 7.3-7.7 & 1.50 & $\begin{array}{l}0.28- \\
0.31\end{array}$ & $.034-0.37$ & $0.42-0.46$ & $0.45-0.49$ \\
\hline $\begin{array}{l}\text { Northern } \\
\text { Bobwhite }\end{array}$ & $\begin{array}{l}\text { Take } \\
\text { off }\end{array}$ & 0.199 & 0.0243 & 2.44 & 19.9 & 3.25 & - & - & - & 1.25 \\
\hline Chukar & $\begin{array}{l}\text { Take } \\
\text { off }\end{array}$ & 0.4915 & 0.0483 & 2.64 & 16.1 & 2.87 & - & - & - & 1.62 \\
\hline $\begin{array}{l}\text { Ring Necked } \\
\text { Pheasant }\end{array}$ & $\begin{array}{l}\text { Take } \\
\text { off }\end{array}$ & 0.9434 & 0.1002 & 2.64 & 11 & 2.34 & - & - & - & 1.37 \\
\hline Turkey & $\begin{array}{l}\text { Take } \\
\text { off }\end{array}$ & 5.275 & 0.3453 & 2.79 & 7.6 & 2.32 & - & - & - & 1.26 \\
\hline $\begin{array}{l}\text { Blue Breasted } \\
\text { Quail }\end{array}$ & $\begin{array}{l}\text { Take } \\
\text { off }\end{array}$ & 0.0436 & 0.0098 & 2.44 & 23.2 & 4.81 & - & - & - & 2.42 \\
\hline Harris Hawk & $\begin{array}{l}\text { Take } \\
\text { off }\end{array}$ & 0.92 & 0.119 & 2.60 & 5.8 & 4.13 & - & - & - & 2.07 \\
\hline Pigeon & $\begin{array}{l}\text { Take } \\
\text { off }\end{array}$ & 0.307 & 0.0352 & 2.48 & 9.1 & 2.62 & - & - & - & 1.19 \\
\hline
\end{tabular}




\section{Figure 4 (on next page)}

3D scatterplot of values for Chukars modeled for the first 70 days of growth.

3D scatterplot of values for Chukars modeled for the first 70 days of growth. 2D projections of the values are shown on each axis-pair plane with grey circles. Age, pectoral limb muscle mass, wing loading, and WAIR performance data are from Heers and Dial. (2015). Maximum WAIR angle was limited to 100 degrees. Regressions were neither linear nor unimodal suggesting a complex interaction between musculoskeleletal and aerofoil ontogeny and performance. Mass $(\mathrm{g})$ was estimated from age by the quadratic equation $5.730818+$ $3.472647 * x+-0.011605 * x^{2}+0.000661 * x^{3}\left(R^{2}=0.9902\right) ;$ only ages less than 100 days were used. Percent pectoral mass was estimated from mass by the quadratic equation $0.858022+$ $0.231592 * x-0.000658 * x^{2}+5.9340^{-7} * x^{3}\left(R^{2}=0.92\right)$. Wing loading was estimated from mass by the quadratic equation $1.692164+-0.018717 * x+8.756264^{-5 *} x^{2}+-9.483335^{-8 *} x^{3}$ $\left(R^{2}=0.69\right)$. Maximum WAIR angle was estimated from mass by the quadratic equation $38.119489+1.137820 * x+-0.007969 * x^{2}+1.925223 e-05 * x^{3}\left(R^{2}=0.9575\right)$. 


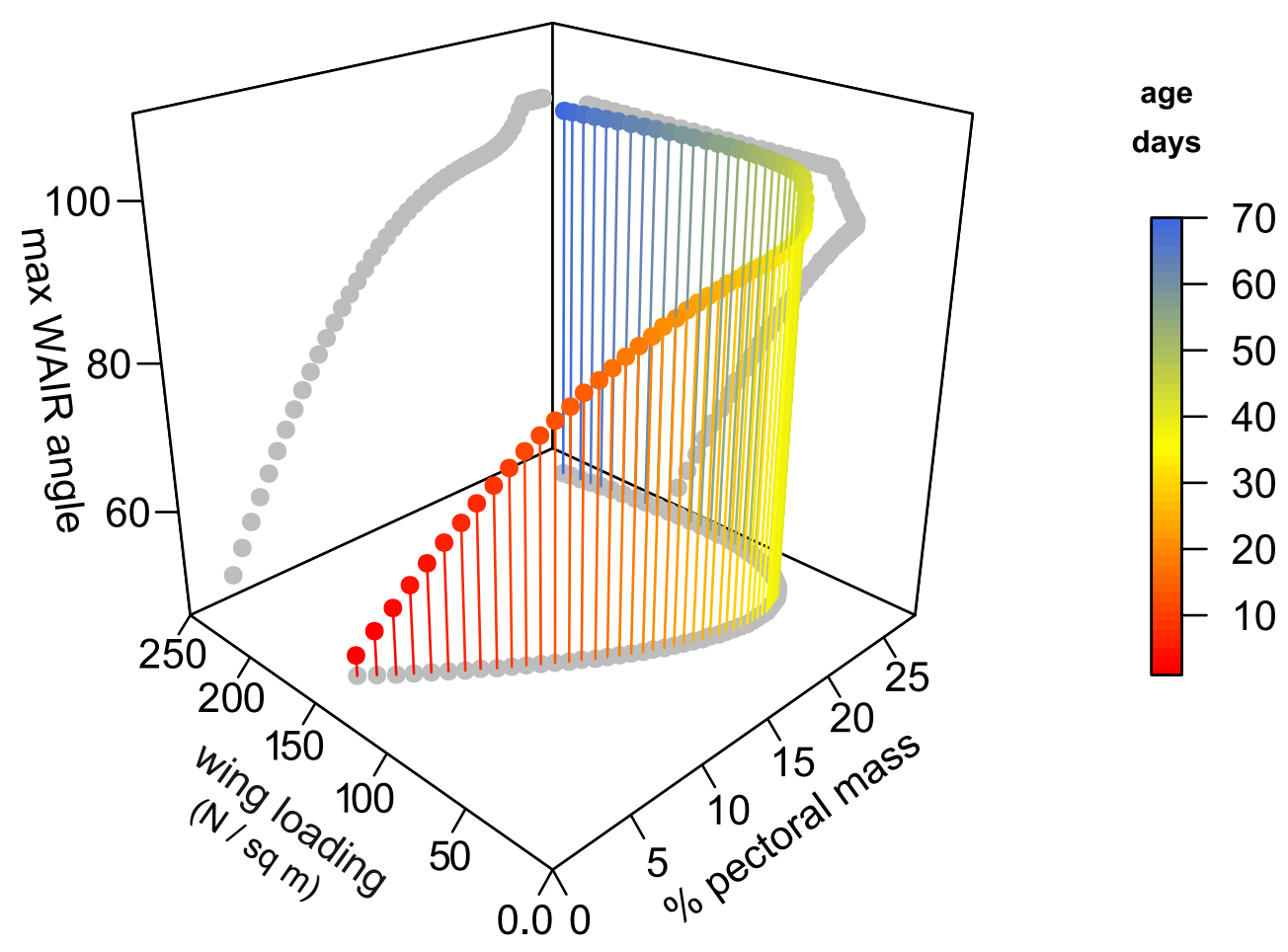




\section{Figure 5 (on next page)}

Regression of measured wing loading versus maximum

Regression of measured wing loading versus maximum WAIR angle in Chukar chicks aged 315 day post hatching and estimates for selected non-avian theropods. Chuckar data are from Heers and Dial (2015). Large circles denote Chukar values with their age given as the number inside. Regression for Chuckar data is $100.17-20.824 x, R 2=0.848$. Small circles denote estimated paravian theropods. Only specimens with wing loading values comparable to those seen in Chukars $\left(<2.0 \mathrm{~g} / \mathrm{cm}^{2,}=196 \mathrm{~N} / \mathrm{m}^{2}\right)$ were included. Demarcation of quadrupedal crawling to WAIR at 65 degrees was based on Jackson et al. (2009). Non-avian theropods are: f1, Anchiornis huxleyi BMNHCPH828; f2, Anchiornis huxleyi LPM B00169; f3, Aurornis xui YFGP-T5198; f4, Changyuanraptor yangi HG B016; f5, Eosinopteryx brevipenna YFGP-T5197; f6, Microraptor gui BMNHC PH 881; f7, M. gui IVPP V 13352; f8, M. hanqingi LVH 0026 (light mass estimate); f9, M. hanqingi LVH 0026 (heavy mass estimate). 


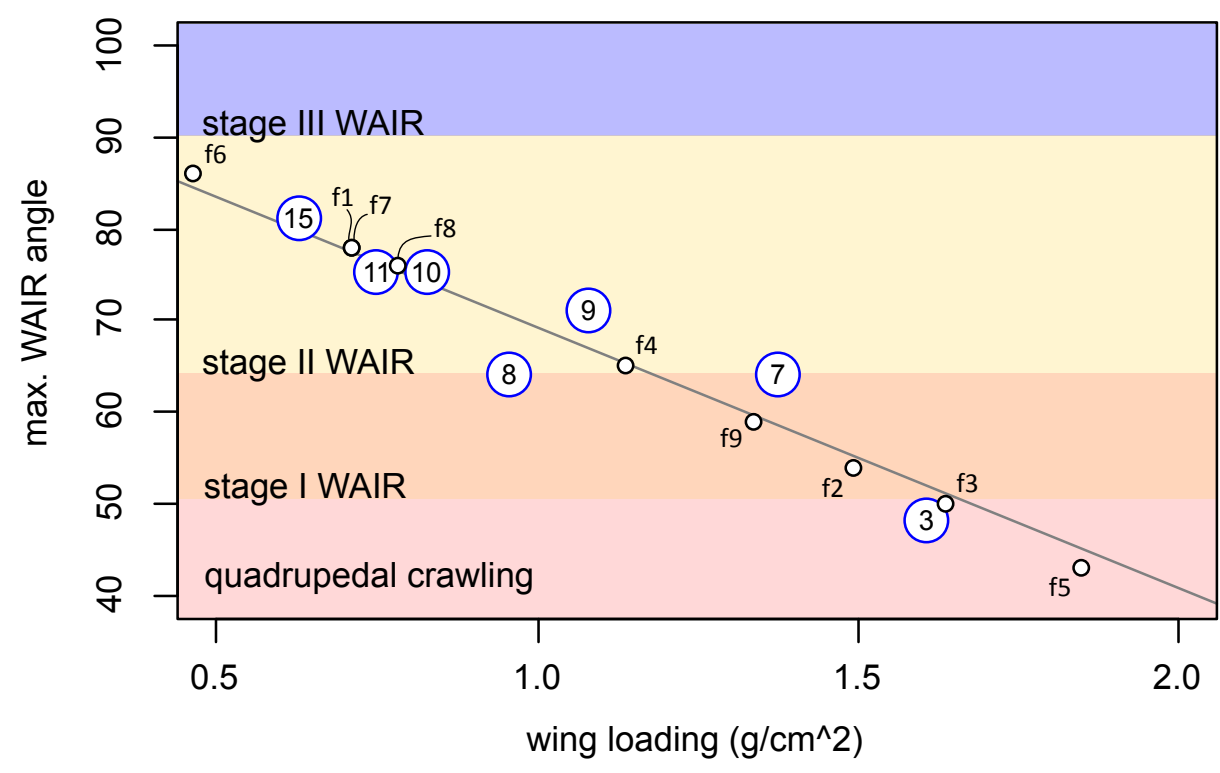




\section{Table 3 (on next page)}

Table of body wight support values across specimens under 90 degree flap angle.

Body weight (bw) support values across non-avian and basal avian taxa under three different flapping frequency estimators (see text for description). Calculations are based on the 90 degree flap angle permutation at two velocity of the centre of mass $(0.6$ and $1.5 \mathrm{~m} / \mathrm{s})$. This correspond to recorded velocity of earliest WAIR capable juveniles $(0.6 \mathrm{~m} / \mathrm{s})$ and adult (1.5 $\mathrm{m} / \mathrm{s}$ ) Chukars (Tobalske and Dial 2007). 


\begin{tabular}{|c|c|c|c|c|c|c|c|c|c|}
\hline Taxa & Specimen & $\mathrm{m} / \mathrm{s}$ & bw All & bw GF & bw MOD & $\mathrm{m} / \mathrm{s}$ & bw All & bw GF & bw MOD \\
\hline Anchiornis & BMNHCPH828 & 1.5 & 0.24 & 0.22 & 0.22 & 0.6 & 0.17 & 0.15 & 0.15 \\
\hline Anchiornis & LPM B00169 & 1.5 & 0.10 & 0.09 & 0.12 & 0.6 & 0.06 & 0.06 & 0.08 \\
\hline Archaeopteryx & 11th & 1.5 & $\begin{array}{r}0.70 / \\
0.37\end{array}$ & $\begin{array}{r}0.62 / \\
0.33\end{array}$ & $\begin{array}{r}0.78 / \\
0.46\end{array}$ & 0.6 & $\begin{array}{r}0.52 / \\
0.27\end{array}$ & $\begin{array}{r}0.45 / \\
0.23\end{array}$ & $\begin{array}{r}0.59 / \\
0.34\end{array}$ \\
\hline Archaeopteryx & Berlin & 1.5 & $\begin{array}{r}0.67 / \\
0.38 \\
\end{array}$ & $\begin{array}{r}0.60 / \\
0.34 \\
\end{array}$ & $\begin{array}{r}0.74 / \\
0.46 \\
\end{array}$ & 0.6 & $\begin{array}{r}0.50 / \\
0.27 \\
\end{array}$ & $\begin{array}{r}0.43 / \\
0.24 \\
\end{array}$ & $\begin{array}{r}0.56 / \\
0.34 \\
\end{array}$ \\
\hline Archaeopteryx & London & 1.5 & $\begin{array}{r}0.57 / \\
0.28\end{array}$ & $\begin{array}{r}0.50 / \\
0.25\end{array}$ & $\begin{array}{r}0.67 / \\
0.37\end{array}$ & 0.6 & $\begin{array}{r}0.42 / \\
0.20\end{array}$ & $\begin{array}{r}0.37 / \\
0.17\end{array}$ & $\begin{array}{r}0.51 / \\
0.27\end{array}$ \\
\hline Archaeopteryx & Munich & 1.5 & $\begin{array}{r}0.66 / \\
0.39 \\
\end{array}$ & $\begin{array}{r}0.59 / \\
0.34 \\
\end{array}$ & $\begin{array}{r}0.68 / \\
0.43 \\
\end{array}$ & 0.6 & $\begin{array}{r}0.48 / \\
0.28 \\
\end{array}$ & $\begin{array}{r}0.42 / \\
0.24 \\
\end{array}$ & $\begin{array}{r}0.51 / \\
0.32 \\
\end{array}$ \\
\hline Archaeopteryx & Thermopolis & 1.5 & $\begin{array}{r}0.71 / \\
0.41\end{array}$ & $\begin{array}{r}0.63 / \\
0.37\end{array}$ & $\begin{array}{r}0.75 / \\
0.47\end{array}$ & 0.6 & $\begin{array}{r}0.52 / \\
0.29 \\
\end{array}$ & $\begin{array}{r}0.46 / \\
0.26\end{array}$ & $\begin{array}{r}0.56 / \\
0.34\end{array}$ \\
\hline Archaeopteryx & Eichstatt & 1.5 & $\begin{array}{r}0.42 / \\
0.29\end{array}$ & $\begin{array}{r}0.38 / \\
0.26\end{array}$ & $\begin{array}{r}0.39 / \\
0.28\end{array}$ & 0.6 & $\begin{array}{r}0.30 / \\
0.20\end{array}$ & $\begin{array}{r}0.26 / \\
0.17\end{array}$ & $\begin{array}{r}0.27 / \\
0.19\end{array}$ \\
\hline Aurornis & YFGP-T5198 & 1.5 & 0.08 & 0.07 & 0.10 & 0.6 & 0.05 & 0.05 & 0.07 \\
\hline Caudipteryx & IVPP 12344 & 1.5 & 0.01 & 0.01 & 0.02 & 0.6 & 0.01 & 0.00 & 0.01 \\
\hline Caudipteryx & IVPP 12430 & 1.5 & 0.01 & 0.01 & 0.01 & 0.6 & 0.00 & 0.00 & 0.01 \\
\hline Changyuraptor & HG B016 & 1.5 & 0.11 & 0.10 & 0.25 & 0.6 & 0.05 & 0.05 & 0.14 \\
\hline Citipati & MPC-D100/971 & 1.5 & 0.03 & 0.03 & 0.03 & 0.6 & 0.02 & 0.02 & 0.02 \\
\hline Eosinopteryx & YFGP-T5197 & 1.5 & 0.12 & 0.11 & 0.12 & 0.6 & 0.08 & 0.07 & 0.08 \\
\hline Jianchangosaurus & 41HIII-0308A & 1.5 & 0.00 & 0.00 & 0.00 & 0.6 & 0.00 & 0.00 & 0.00 \\
\hline Jinfengopteryx & $\begin{array}{l}\text { CAGS-IG 04- } \\
0801\end{array}$ & 1.5 & 0.03 & 0.02 & 0.03 & 0.6 & 0.02 & 0.01 & 0.02 \\
\hline Mahakala & IGM 100/1033 & 1.5 & 0.04 & 0.03 & 0.05 & 0.6 & 0.02 & 0.02 & 0.03 \\
\hline Mei long & DNHM D2154 & 1.5 & 0.01 & 0.01 & 0.02 & 0.6 & 0.01 & 0.01 & 0.01 \\
\hline Mei long & IVPP V12733 & 1.5 & 0.01 & 0.01 & 0.01 & 0.6 & 0.00 & 0.00 & 0.01 \\
\hline Microraptor & BMNHC PH 881 & 1.5 & 0.49 & 0.43 & 0.50 & 0.6 & 0.35 & 0.31 & 0.36 \\
\hline Microraptor & IVPP V 13352 & 1.5 & 0.28 & 0.25 & 0.42 & 0.6 & 0.20 & 0.17 & 0.32 \\
\hline Microraptor hanqingi & LVH 0026 & 1.5 & 0.14 & 0.12 & 0.24 & 0.6 & 0.08 & 0.07 & 0.15 \\
\hline Oviraptor in sedis & $\begin{array}{l}\text { MPC- } \\
\text { D100/1018 }\end{array}$ & 1.5 & 0.05 & 0.04 & 0.03 & 0.6 & 0.03 & 0.03 & 0.02 \\
\hline Protarchaeopteryx & GMV2125 & 1.5 & 0.00 & 0.00 & 0.01 & 0.6 & 0.00 & 0.00 & 0.00 \\
\hline Similicaudipteryx & STM22-6 & 1.5 & 0.02 & 0.02 & 0.05 & 0.6 & 0.01 & 0.01 & 0.03 \\
\hline Similicaudipteryx & STM4-1 & 1.5 & 0.02 & 0.02 & 0.02 & 0.6 & 0.01 & 0.01 & 0.01 \\
\hline Sinocalliopteryx & JMP-V-05-8-01 & 1.5 & 0.00 & 0.00 & 0.00 & 0.6 & 0.00 & 0.00 & 0.00 \\
\hline Sinornithoides & IVPP V9612 & 1.5 & 0.01 & 0.01 & 0.01 & 0.6 & 0.00 & 0.00 & 0.01 \\
\hline Sinornithosaurus & NGMC-91A & 1.5 & 0.01 & 0.01 & 0.01 & 0.6 & 0.00 & 0.00 & 0.01 \\
\hline Sinornithosaurus & $\begin{array}{l}\text { Sullivan et al. } \\
2010\end{array}$ & 1.5 & 0.05 & 0.05 & 0.06 & 0.6 & 0.03 & 0.03 & 0.04 \\
\hline Sinosauropteryx & NICP 127587 & 1.5 & 0.00 & 0.00 & 0.00 & 0.6 & 0.00 & 0.00 & 0.00 \\
\hline Sinosauropteryx & NIGP 127586 & 1.5 & 0.00 & 0.00 & 0.00 & 0.6 & 0.00 & 0.00 & 0.00 \\
\hline Sinovenator & IVPP V11977 & 1.5 & 0.01 & 0.01 & 0.01 & 0.6 & 0.00 & 0.00 & 0.01 \\
\hline Tianyuraptor & STM1-3 & 1.5 & 0.00 & 0.00 & 0.00 & 0.6 & 0.00 & 0.00 & 0.00 \\
\hline Troodon Embryo & MOR 246-1 & 1.5 & 0.04 & 0.04 & 0.03 & 0.6 & 0.02 & 0.02 & 0.02 \\
\hline Xiaotingia & STM 27-2 & 1.5 & 0.03 & 0.03 & 0.05 & 0.6 & 0.02 & 0.02 & 0.03 \\
\hline Yixianosaurus & IVPP 12638 & 1.5 & $\begin{array}{r}0.03 / \\
0.02 \\
\end{array}$ & $\begin{array}{r}0.03 / \\
0.02\end{array}$ & $\begin{array}{r}0.05 / \\
0.03 \\
\end{array}$ & 0.6 & $\begin{array}{r}0.02 / \\
0.01\end{array}$ & $\begin{array}{r}0.02 / \\
0.01\end{array}$ & $\begin{array}{r}0.03 / \\
0.02\end{array}$ \\
\hline Yulong & 41HIII-0107 & 1.5 & 0.03 & 0.03 & 0.04 & 0.6 & 0.02 & 0.02 & 0.02 \\
\hline Zhenyuanlong & JPM-0008 & 1.5 & 0.02 & 0.01 & 0.04 & 0.6 & 0.01 & 0.01 & 0.03 \\
\hline
\end{tabular}


1

PeerJ reviewing PDF | (2016:01:8695:2:0:NEW 25 May 2016) 